\title{
Experimental Evaluation of Oxygen-Enriched Air and Emulsified Fuels in a Single-Cylinder Diesel Engine
}

\section{Volume 1: Concept Evaluation}

by R.R. Sekar, W.W. Marr, R.L. Cole, and T.J. Marciniak

Energy Systems Division,

Argonne National Laboratory, 9700 South Cass Avenue, Argonne, Illinois 60439

November 1991

Work sponsored by United States Department of Energy, Assistant Secretary for Conservation and Renewable Energy, Office of Industrial Technologies 


\section{Contents}

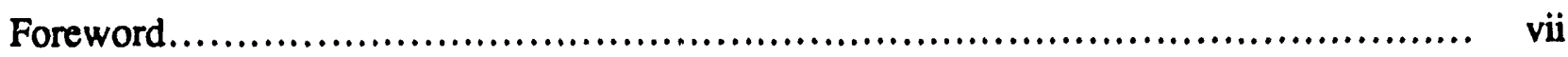

Acknowledgments............................................................... viii

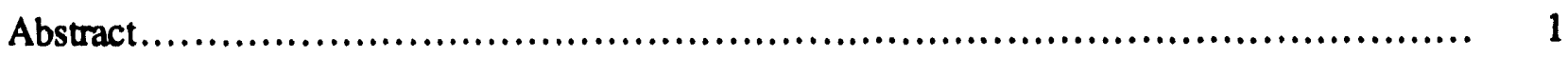

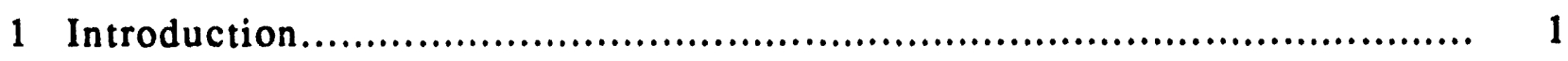

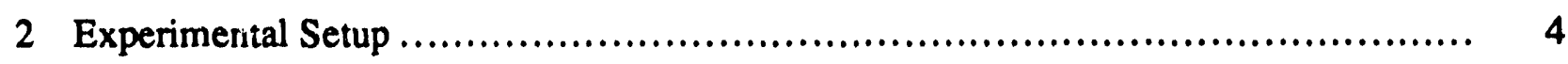

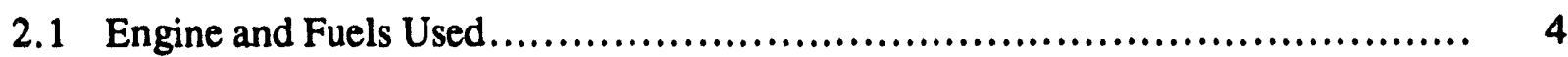

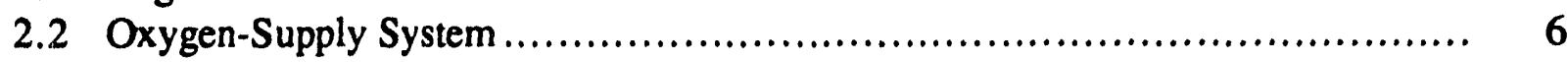

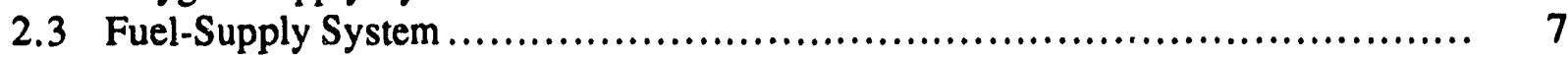

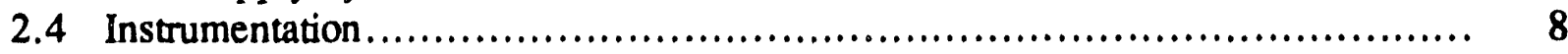

2.5 Test Matrix ................................................................ 9

3 Discussion of the Data.......................................................... 10

3.1 Test Series I: Tests with Bottled Oxygen..................................... 10

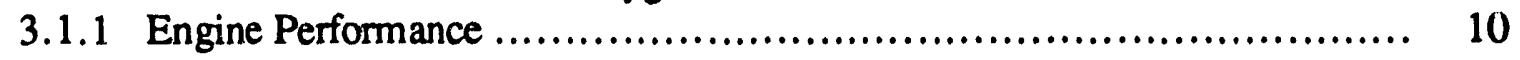

3.1 .2 Thermal Efficiency....................................................... 11

3.1.3 Emissions of Nitrogen Oxide............................................ 12

3.1.4 Particulate-Matter Emissions and Smoke .................................. 14

3.1 .5 Ignition Delay ......................................................... 17

3.1.6 Cylinder Pressures.................................................... 17

3.1 .7 Heat-Release Rates.................................................... 23

3.1.8 Combustion Temperatures ............................................. 25

3.2 Test Series II: Tests with an Oxygen-Enrichment Membrane..................... 27

3.3 Problems Encountered during Experiments .................................. 27

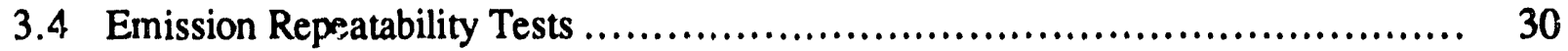

4 Conclusions and Recommendations............................................ 36

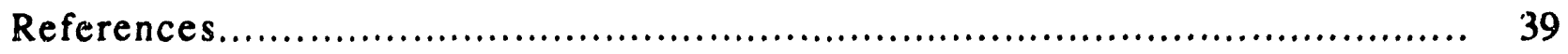

\section{Figures}

1 Diagrams of the Experimental Setup.......................................... 5

2 Experimental Setup for Series I Experiments................................ 6 


\section{Figures (Cont'd)}

3 Diagram of Oxygen-Supply System for Series II Engine Tests........................ 7

4 Experimental Setup for Series II Experiments.................................. 8

5 Maximum Attainable Power with No. 2 Diesel Fuel .................................. 11

6 Maximum Attainable Power with No. 4 Diesel Fuel ................................... 11

7 Effect of Water Content on Thermal Efficiency ..................................... 13

8 Effect of Oxygen on Thermal Efficiency ............................................ 13

9 Effect of Water and Oxygen on $\mathrm{NO}_{\mathrm{x}}$ Emissions, No. 2 Diesel Fuel .................... 14

10 Effect of Water and Oxygen on $\mathrm{NO}_{x}$ Emissions, No. 4 Diesel Fuel .................... 14

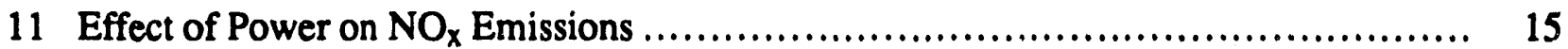

12 Effect of Oxygen on Particulate-Matter Emissions............................... 15

13 Effect of Power on Particulate-Matter Emissions .................................. 16

14 Effect of Water Content on Particulate-Matter Emissions............................. 16

15 Effect of Power Output and Oxygen Level on Ignition Delay ........................ 18

16 Effect of Water Content in the Fuel and Power Output on Ignition Delay ............... 18

17 Effect of Using Less-Refined Fuel on Ignition Delay ................................ 19

18 Effect of Power Output and Oxygen Level on Peak Cylinder Pressure ................... 19

19 Comparison of Peak Cylinder Pressures with No. 2 and No. 4 Diesel Fuels............ 20

20 Effect of Intake Oxygen Levels on Cylinder Pressure ............................ 21

21 Effect of Intake Oxygen Levels on Rates of Cylinder Pressure Rise ................... 21

22 Effect of Water in the Fuels, Increased Oxygen in the Intake Air, and Increased Power Level on Cylinder Pressure .................................................... 22

23 Comparison of Cylinder Pressures with No. 2 and No. 4 Diesel Fuels ................ 22 


\section{Figures (Cont'd)}

24 Comparison Rates of Pressure Rise with No. 2 and No. 4 Diesel Fuels ......... 23

25 Effect of Oxygen on Cumulative Heat-Release Rates............................ 24

26 Effect of Water on Cumulative Heat-Release Rates ............................. 24

27 Cumulative Heat-Release Rates with No. 2 and No. 4 Diesel Fuels................ 25

28 Effect of Oxygen Level on Calculated Gas Temperatures ........................ 26

29 Effect of Water in the Fuel on Calculated Gas Temperatures ..................... 26

30 Effect $\mathrm{c}_{\mathrm{f}}$ Injection Timing on Thermal Efficiency............................... 28

31 Effect of Injection Timing on $\mathrm{NO}_{\mathrm{x}}$ Emissions ............................... 28

32 Trade Off between Brake-Specific $\mathrm{NO}_{\mathrm{x}}$ and Brake-Specific Fuel Consumption .......... 29

33 Effect of Injection Timing on Particulate Matter $\ldots \ldots \ldots \ldots \ldots \ldots \ldots \ldots \ldots \ldots \ldots \ldots \ldots . \ldots \ldots$

34 Emission Repeatability Tests, Particulate-Matter Measurements: 50 bhp................. 33

35 Emission Repeatability Tests, $\mathrm{NO}_{\mathrm{x}}$ Measurements: 50 bhp............................ 33

36 Emission Repeatability Tests, Smoke Measurements: 50 bhp.................... 34

37 Emission Repeatability Tests, Particulate-Matter Measurements: 25 bhp................. 34

38 Emission Repeatability Tests, $\mathrm{NO}_{\mathrm{x}}$ Measurements: 25 bhp............................. 35

39 Emission Repeatability Tests, Smoke Measurements: 25 bhp..................... 35

\section{Tables}

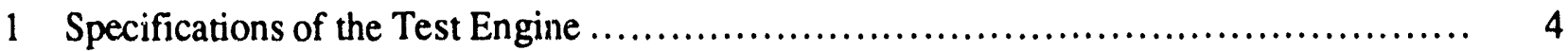

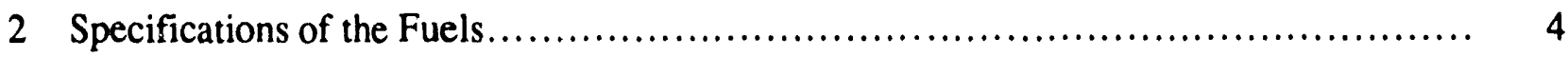

3 Emissions Repeatability Tests: First Test Sequence $\ldots \ldots \ldots \ldots \ldots \ldots \ldots \ldots \ldots \ldots \ldots \ldots \ldots, 31$

4 Emissions Repeatability Tests: Second Test Sequence ........................... 32 


\section{Foreword}

This report contains the data gathered from tests conducted on a single-cylinder diesel engine to study the benefits and problems of oxygen-enriched diesel combustion and the use of water-emulsified and low-grade diesel fuels. This research, funded by the Office of Industrial Tec hnologies (OIT) in the United States Department of Energy, is being conducted in support of the Industrial Cogeneration Program. The report is made up of two volumes. Volume 1 con ains the description of the experiments, selected data points, discussion of trends, and conclusions and recommendations; Volume 2 contains the data sets. With the two-volume approach, readers can find information at the desired level of detail, depending on individual interest or need. 


\section{Acknowledgments}

The authors would like to acknowledge the following individuals from Argonne National Laboratory for their assistance in the preparation and production of Volume 1 of this report: Laurie Culbert, IPD-TCS, graphics; Leslie Crosser, IPD-TCS, word processing; and Kevin Brown, IPD-TCS, technical editing. 


\title{
Experimental Evaluation of Oxygen-Enriched Air and Emulsifled Fuels in a Single-Cylinder Diesel Engine
}

\author{
Volume 1: \\ Concept Evaluation
}

by

\author{
R.R. Sekar, W.W. Marr, R.L. Cole, and T.J. Marciniak
}

\begin{abstract}
The performance of a single-cylinder, direct-injection diesel engine was measured with intake oxygen levels of up to $35 \%$ and fuel water contents of up to $20 \%$. Because a previous study indicated that the use of a less-expensive fuel would be more economical, two series of tests with No. 4 diesel fuel and No. 2 diesel fuel were conducted. To control the emissions of nitrogen oxides $\left(\mathrm{NO}_{\mathbf{x}}\right)$, water was introduced into the combustion process in the form of water-emulsified fuel, or the fuel injection timing was retarded. In the first series of tests, compressed oxygen was used; in the second series of tests, a hollow-tube membrane was used. Steady-state engine performance and emissions data were obtained. Test results indicated a large increase in engine power density, a slight improvement in thermal efficiency, and significant reductions in smoke and particulate-matter emissions. Although $\mathrm{NO}_{\mathrm{x}}$ emissions increased, they could be controlled by introducing water and retarding the injection timing. The results further indicated that thermal efficiency is slightly increased when moderately water-emulsified fuels are used, because a greater portion of the fuel energy is released earlier in the combustion process. Oxygen-enriched air reduced the ignition delay and caused the heat-release rate and cumulative heat-release rates to change measurably. Even at higher oxygen levels, $\mathrm{NO}_{\mathrm{x}}$ emissions decreased rapidly when the timing was retarded, and the amount of smoke and the level of particulate-matter emissions did not significantly increase. The single-cylinder engine tests confirmed the results of an earlier technical assessment and further indicated a need for a low-pressure-drop membrane specifically designed for oxygen enrichment.
\end{abstract}

\section{Introduction}

The concept of using oxygen-enriched air for diesel engine combustion has been studied by several researchers over the last two decades. Oxygen enrichment decreases smoke and other exhaust emissions and improves thermal efficiency. Wartinbee ${ }^{1}$ considered and rejected the application of the concept to spark-ignition engines because of the difficulties involved in 
controlling the emissions of nitrogen oxide $\left(\mathrm{NO}_{\mathbf{x}}\right)$ caused by oxygen enrichment. Quader ${ }^{2}$ studied the combustion mechanisms of oxygen enrichment, and the concept was again rejected because of $\mathrm{NO}_{\mathrm{x}}$ emissions and fuel consumption penalties. Ghojel ${ }^{3}$ and $\mathrm{Iida}^{4}$ published their work on indirect-injected and direct-injected diesel engines, respectively. Later, lida and Sato ${ }^{5}$ found that a reduction in ignition delay made the control of $\mathrm{NO}_{\mathrm{x}}$ emissions possible by retarding injection timing.

The oxygen-enrichment concept, as applied to diesel engines, deserves a more comprehensive review in the context of the standards for particulate-matter emissions proposed by the U.S. Environmental Protection Agency (EPA), which will go into effect in 1994. Because oxygen enrichment can potentially reduce smoke and particulate-matter emissions significantly, this technology may be orie of the solusions to the problems of emissions from diesel engines.

Recent work 6,7 by engine developers indicate a renewed interest in the oxygen-enrichment concept. In parallel developments funded primarily by the U.S. Department of Energy (DOE), significant advances have been reported in the development of practical oxygen-enrichment devices, such as asymmetric hollow-fiber membranes, that could be used for various applications. ${ }^{8,9,10}$ Argonne National Laboratory (ANL) undertook a systematic research project of the application of oxygen enrichment to stationary diesel engines. Although the technology offered several advantages in performance and emissions, oxygen-enriched diesel engines that lack a definite means of controlling the $\mathrm{NO}_{\mathrm{x}}$ emissions could not be commercialized in stationary or transportation applications in the United States. Hence, the use of water injection, in the form of emulsified fuel, was included as part of the ANL research. Water injection has been studied previously and reported to reduce $\mathrm{NO}_{\mathrm{x}}$ emissions. ${ }^{11,12}$ Moreover, retarding the timing of fuel injection reduces $\mathrm{NO}_{\mathrm{x}}$ emissions from diesel engines. But such a change in injection timing usually increases fuel consumption. The penalty in brake-specific fuel consumption (bsfc) is eliminated when, simultaneously, injection timing is retarded and the combustion air is enriched with oxygen. 5

Studies 13,14 of the performance, emissions, and economic aspects of applying oxygen enrichment and emulsified fuels to diesel engines revealed that significant decreases in ignition delays and emissions of smoke and particulate matter (but not $\mathrm{NO}_{\mathrm{x}}$ ) are possible. Meanwhile, excellent increases in power density and slight increases in efficiency could be achieved. In the experimental phase of the project, ANL conducted tests on a single-cylinder diesel engine so obtain data on performance, emissions, and cylinder pressure. In the first series of tests, bottled oxygen was used to enhance the oxygen content of the inlet air. In the second series of tests, an actual membrane separation unit was used to provide oxygen-enriched air, and the timing of fuel injection was varied in order to obtain performance and emissions data.

The objectives of this program were to:

1. Measure the performance of a diesel engine operated with oxygen-enriched air, water-emulsified fuel, and less-refined fuel;

2. Demonstrate the operation of a diesel engine coupled to an oxygen-enrichment membrane; and 
3. Measure the effects of oxygen-enriched air, water-emulsified fuel, and lessrefined fuel on emissions.

The performance parameters that were measured included increased power (by increasing the fueling rate to consume the added oxygen), thermal efficiency, cylinder pressure as a function of crank angle, heat release as a function of crank angle, and ignition delay. In the first series of tests, air containing $21-35 \%$ oxygen was used, and in the second series of tests, air containing $21-27 \%$ oxygen was used.

The emissions that were measured included smoke (both qualitative and quantitative), particulate matter, and $\mathrm{NO}_{\mathrm{x}}$. Although the original intent was to use No. 6 fuel as the less-refined fuel, it was felt that No. 4 fuel would be easier to handle because of its lower viscosity. 


\section{Experimental Setup}

\subsection{Engine and Fueis Used}

A single-cylinder, four-stroke, direct-injection diesel engine was used for the experiments. The engine was a one-cylinder version of a heavy-duty diesel engine commonly used in on-highway trucks and in other applications. The major specifications of the base engine are given in Table 1. No hardware changes were made to the basic engine, and the manufacturer's recommendations were used to set up and operate the engine. The engine was designed to run on No. 2 diesel fuel. Water was introduced into the combustion process by emulsifying the two base fuels with distilled water and a small percentage of a stabilizing chemical additive. Three levels of water content were tested with each base fuel. The specifications of the fuels are provided in Table 2.

Diagrams and photographs of the experimental setup are shown in Figs. 1 and 2 for the first series of experiments, during which compressed oxygen from a bank of storage cylinders was

TABLE 1 Specifications of the Test Engine

\begin{tabular}{lc}
\hline \multicolumn{1}{c}{ Parameter } & Value \\
\hline Number of cylinders & 1 \\
Bore x stroke (mm) & $137 \times 165$ \\
Displacement (L) & 2.44 \\
Engine Speed (rpma) & 1800 \\
Injection timing (deg. btdc & 33 \\
Compression ratio & 14.5 \\
Peak cylinder pressure (bar) & 110 \\
\hline
\end{tabular}

aRevolutions per minute

bDegrees before top dead center

TABLE 2 Specifications of the Fuels

\begin{tabular}{lll}
\hline & \multicolumn{2}{c}{ Diesel Fuel Type } \\
\cline { 2 - 3 } & \multicolumn{1}{c}{ No. 2} & No. 4 \\
\hline Kinematic viscosity $\left(c S^{a}\right.$ at $\left.80^{\circ} \mathrm{C}\right)$ & 1.8 & 5.2 \\
Lower heating value $(\mathrm{kJ} / \mathrm{kg})$ & 42,668 & 40,909 \\
Water used for emulsion $(\%$ of fuel weight) & $0,5,10$ & $0,5,10$ \\
Chemical additive (\%) & 0.333 & 1.0 \\
\hline
\end{tabular}

acentistokes 

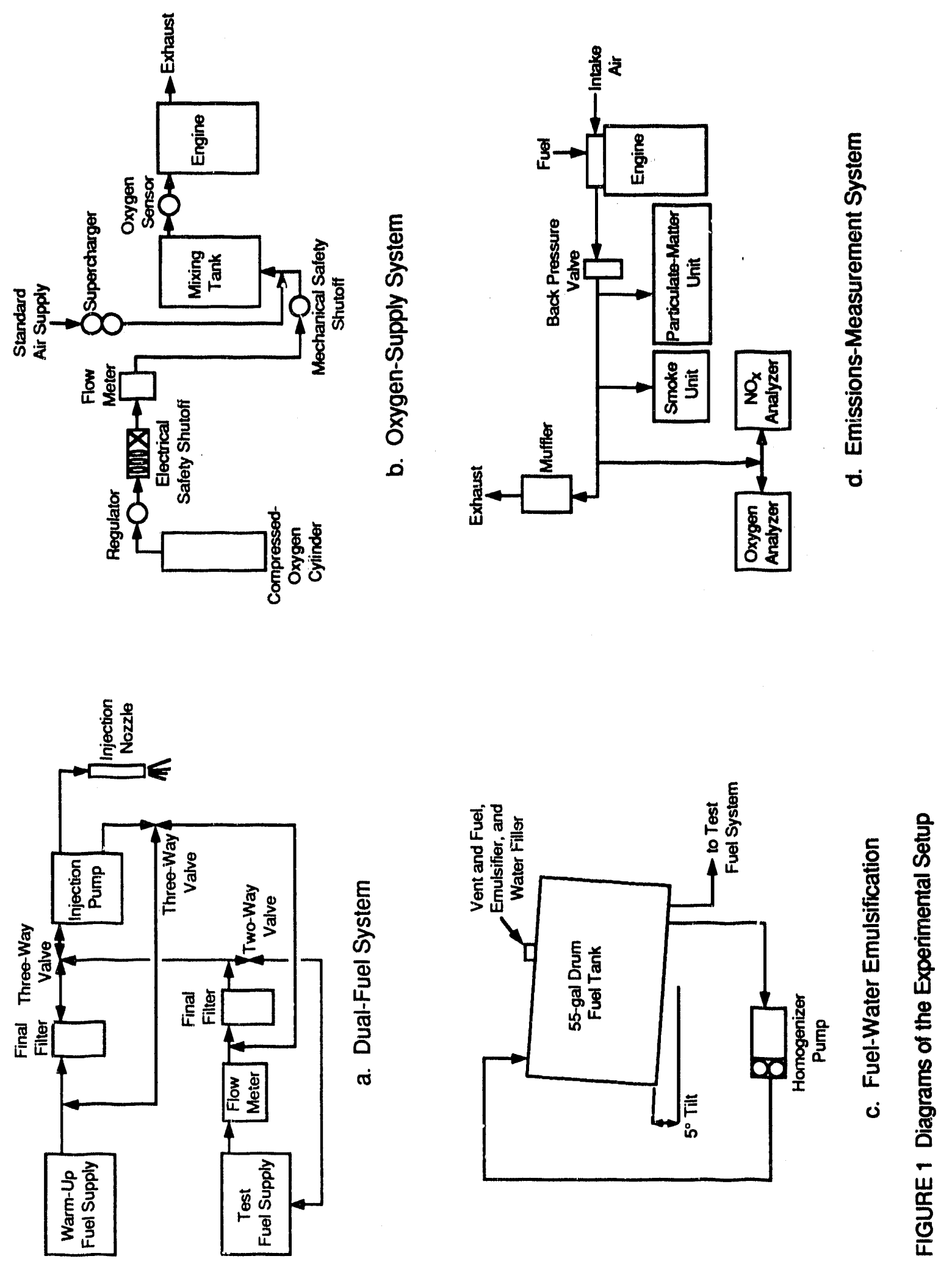

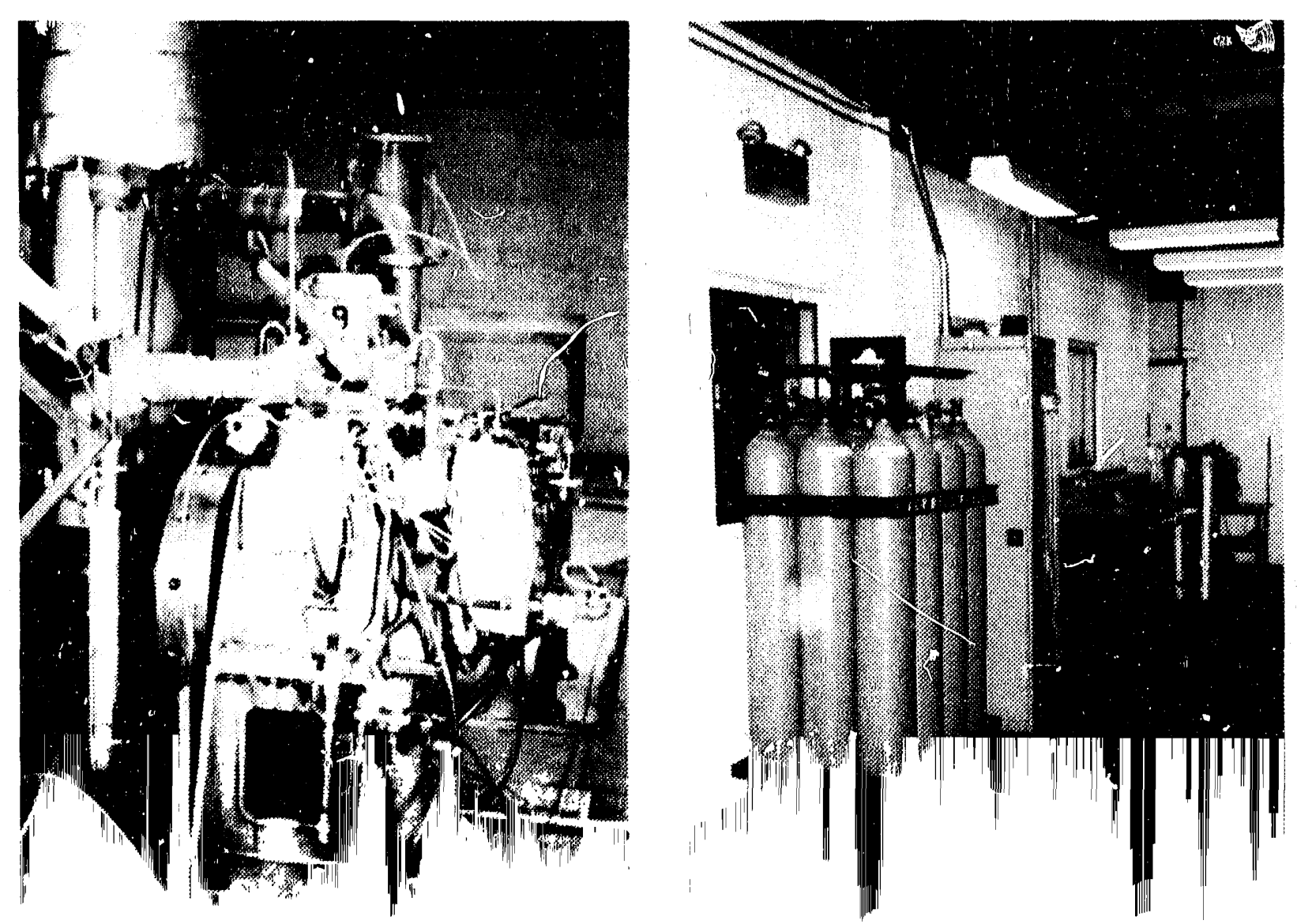


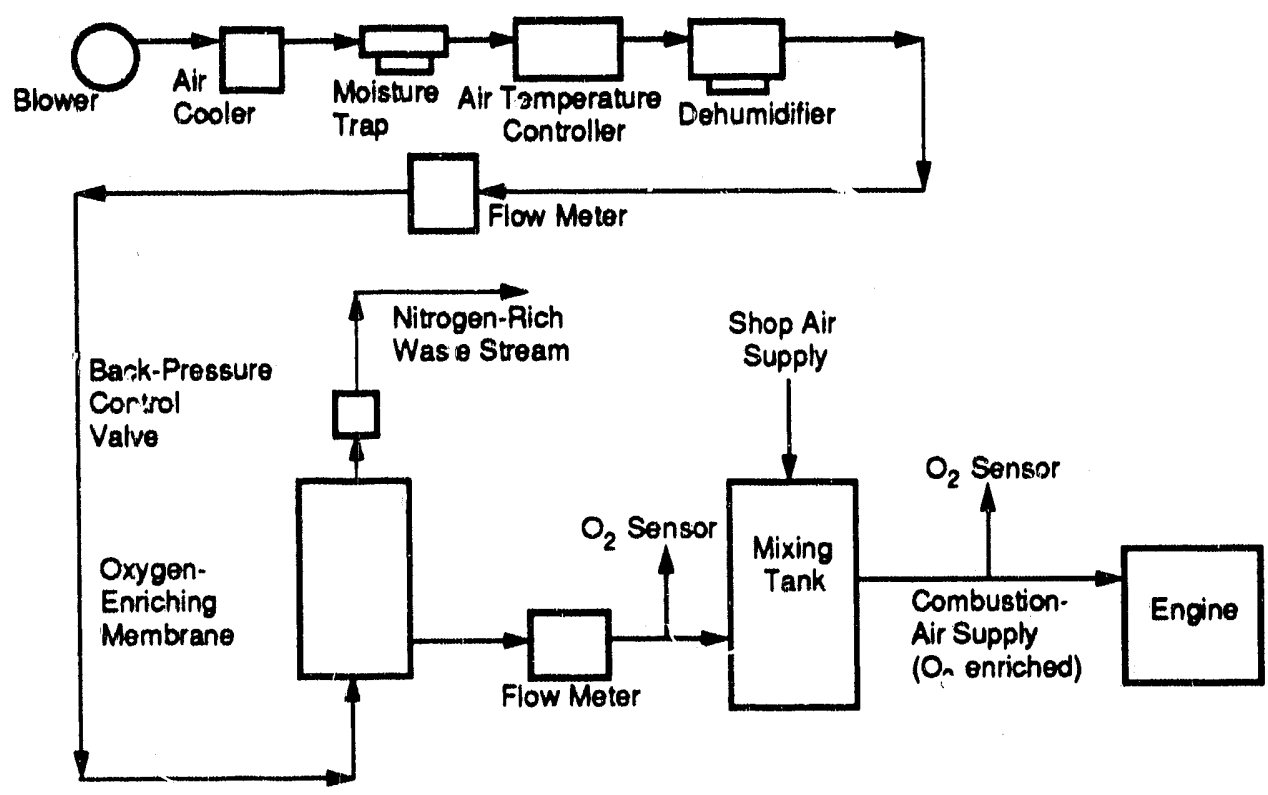

FIGURE 3 Diagram of Oxygen-Supply System for Series II Engine Tests

In the second series of tests, an oxygen-enrichment meml,rane was used. This membrane was originally designed and procured by $\mathrm{DOZ}$ for a different project. because of cost and availability problems, it was decided that the membrane should be used for initial screening tests. On the basis of the data gathered from the membrane tests, ${ }^{8}$ it was clear that the membrane's oxygen-rich stream alone could not provide the entire mass-flow rate required for the diesel engine. Hence, a mixing tank was included in which the oxygen-enriched air provided by the membrane was diluted with shop air.

\subsection{Fuel-Supply System}

A separate fuel-preparation system, shown in Fig. 1c, was installed, and the test fuel was supplied to the engine fuel pump from this system. Fuel preparation encompassed making a fuel emulsion in a tank, keeping it circulated to prevent the water from settling, measuring the massflow rate of the fuel, and maintaining the temperature of the fuel by using a heater. Many problems were encountered in maintaining a consistent fuel emulsion; therefore, additional research into a means of introducing water into the engine-combustion process is needed. Fuel samples were taken immediately before and after each test. The samples were analyzed in the chemistry laboratory for water content, and the average value of the two samples was used in the calculations. 

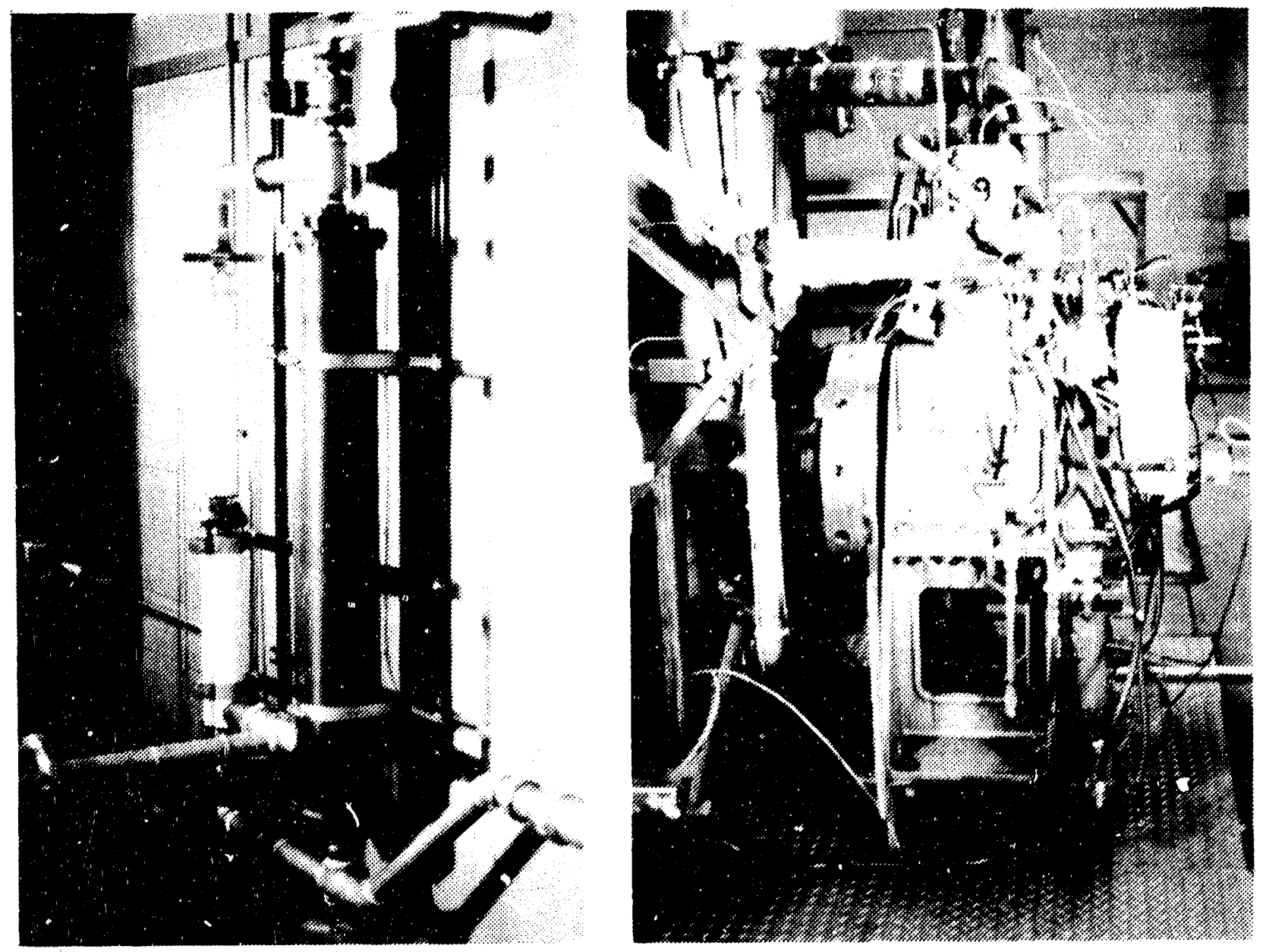

FIGURE 4 Experimental Setup for Series II Experiments

\subsection{Instrumentation}

Most $0^{i}$ the instrumentation used in the tests was standard engine test cell instrumentation. Oxygen flow rates were measured and recorded separately. Additional instrumentation was used in the second phase of the tests to record the performance of the membrane. An AVL piezoelectric transducer located at the combustion surface of the cylinder head was used to measure cylinder pressure. Marks for top dead center and crank angle were referenced by an optical encoder attached to the front of the crankshaft. The signals were processed through an IBM advanced technology computer. Individual cycle pressures and a 30-cycle-average pressure diagram were recordied on a floppy disk for each test. The data were later analyzed by using a heat-release computer code on a personal computer. Only $N \mathrm{O}_{\mathrm{x}}$ and oxygen level were measured in the exhaust gas stream for gaseous emissions. A conventional filter method was used to measure the emissions of particulate matter down to $0.5 \mu \mathrm{m}$ in size. Smoke was measured by the degree of filter darkening caused by reflected light, which was read on a reflectometer scale of $0-100 \%$. More detailed emissions measurements will be made when a scaled-up multicylinder engine is tester. 


\subsection{Test Matrix}

Two base cases were defined for the engine operating with standard air ( $2.1 \%$ oxygen) and No. 2 fuel without water. The 50\%-load base case was defined as the fuel rate required to produce $18.65 \mathrm{~kW}$ (25 bhp). The $100 \%$-load base case was defined as the fuel rate required to produce $37.3 \mathrm{~kW}(50 \mathrm{bhp})$.

All 50\%-load cases (including the 50\%-load base case and cases where oxygen-enriched air, No. 4 fuel, or water-emulsified fuel are used) maintained an intake manifold pressure of $112 \mathrm{~cm} \mathrm{Hg}$ abs. to simulate turbocharging. All 100\%-load cases maintained an intake manifold pressure of $140 \mathrm{~cm} \mathrm{Hg}$ abs. All case maintained an exhaust manifold pressure of $81 \mathrm{~cm} \mathrm{Hg}$ abs. to simulate the back pressure of a turbocharger. All tests were done at 1800 revolutions per minute (rpm), the synchronous speed of an electric generator.

Test runs at each oxygen level were made for the two base cases at three fue ing rates each: (1) fueling rate adjusted to maintain the same power output as the base case, (2) fueling rate adjusted to maintain the same ratio of exhaust oxygen content to intake oxygen content (this fueling rate produced increased power output), and (3) fueling rate adjusted to maintain the oxygen content of the exhaust gases at the same level as the base case (this fueling rate produced the maximum power, but in scime cases, the fueling rate was decreased from this amount to limit exhaust temperature to $\left.590^{\circ} \mathrm{C}\left[1100^{\circ} \mathrm{F}\right]\right)$. Thus, for each nonbase-case condition, there were six test runs.

The intake oxygen level was varied from from $21 \%$ to $35 \%$. Because of the difficulties that were ercountered in preparing the emulsified fuel, the water content of the fuel emulsion ranged from $0 \%$ to $22 \%$. In total, 112 test runs were made, and several graphs were plotted. (Of these graphs, only the most significant trend curves are presented in this report.) Baseline data were rerun frequently during the test program to ensure that the condition of the engine did not change significantly. Although some data had to be discarded because of instrumentation failures, the first test series was completed without any major engine problems.

The main objective of the second series of tests was to demonstrate the practicality of using an oxygen-enrichment membrane as part of a diesel engine. Hence, the test matrix was not as elaborate as in the first series of tests. Forty-four data points were obtained at two oxygen levels, at two water levels in the fuel, and for the same two fuels as in the first series of tests. The base injection timing, which was unaltered throughout the first series of tests, was $33 \mathrm{deg}$. before top dead center (btdc). In addition to the base injection timing of $33 \mathrm{deg}$. btdc, two levels of retarded injection timings, $27 \mathrm{deg}$. btdc and $22 \mathrm{deg}$. btdc, were tested in the second series of tests. 


\section{Discussion of the Data}

Because the engine test data were collected in two series of tests, the discussion and data interpretation are presented in that order. Volume 2, App. A, contains the data in tabular form from Series I, as well as graphs of major parameters of interest. Volume 2, App. B, contains the data tables and graphs obtained from Series II tests. In the text (Volume 1), selected data are presented to emphasize certain points and to illustrate concr. sions.

\subsection{Test Series I: Tests with Bottled Oxygen}

The single-cylinder engine tests completed in the first series of 112 data points contain the effects of oxygen level in the intake air (21-35\% by voiume), the amount of water in the fuel (0-10\% by weight, according to the original plan), the level of engine-power output, the type of base fuel (No. 2 or No. 4 diesel), and the fueling rate, which is closely related to the level of oxygen in the exhaust. The major dependent variables are power output potential; thermal efficiency, which is a direct measure of brake-specific fuel consumption, bsfc; exhaust temperature, which is usually a good indicator of the thermal limits of the engine components; smoke; particulate-matter emissions; $\mathrm{NO}_{\mathbf{x}}$ emissions in the exk.aust; cylinder pressure and heatrelease rates; ignition delay; and calculated combustion gas temperatures.

\subsubsection{Engine Performance}

The power output of a diesel engine is usually limited by the level of exhaust smoke. Smoke increases are caused by incomplete combustion of fuel, which is caused by, among other reasons, the inability of oxygen to reach all of the fuel. The tests showed that even a slight enrichment in the level of oxygen reduces smoke ro a point at which the output is no longer limited by smoke but by limits on exhaust temperature imposed on the engine materials. Figures 5 and 6 show the maximum power potential at various oxygen levels. High-temperature materials, such as silicon-nitride valves, seats, and turbocharger components, would enable the engine to produce even higher power levels until the engine's mechanical limits, as indicated by peak cylinder pressures, are reached. Both No. 2 and No. 4 fuels are capable of producing 140\% higher power at the 50\%-load case and 50\% higher power at the $100 \%$-load case.

Because the concept being tested includes water injection for $\mathrm{NO}_{\mathrm{x}}$ control, the question arises whether such remarkable increases in power density are possible when fuels emulsified with water are used in conjunction with oxygen enrichment. The test data indicate that the water content in the fuel does not affect the gains in power density when No. 2 diesel fuel is used or when No. 4 diesel fuel is used at the 50\%-load setting. However, at the 100\%-load setting with emulsified No. 4 fuel, the maximum power limited by the exhaust temperature showed only a $40 \%$ gain. This fact must be carefully taken into account when the system is scaled up for large installations. 


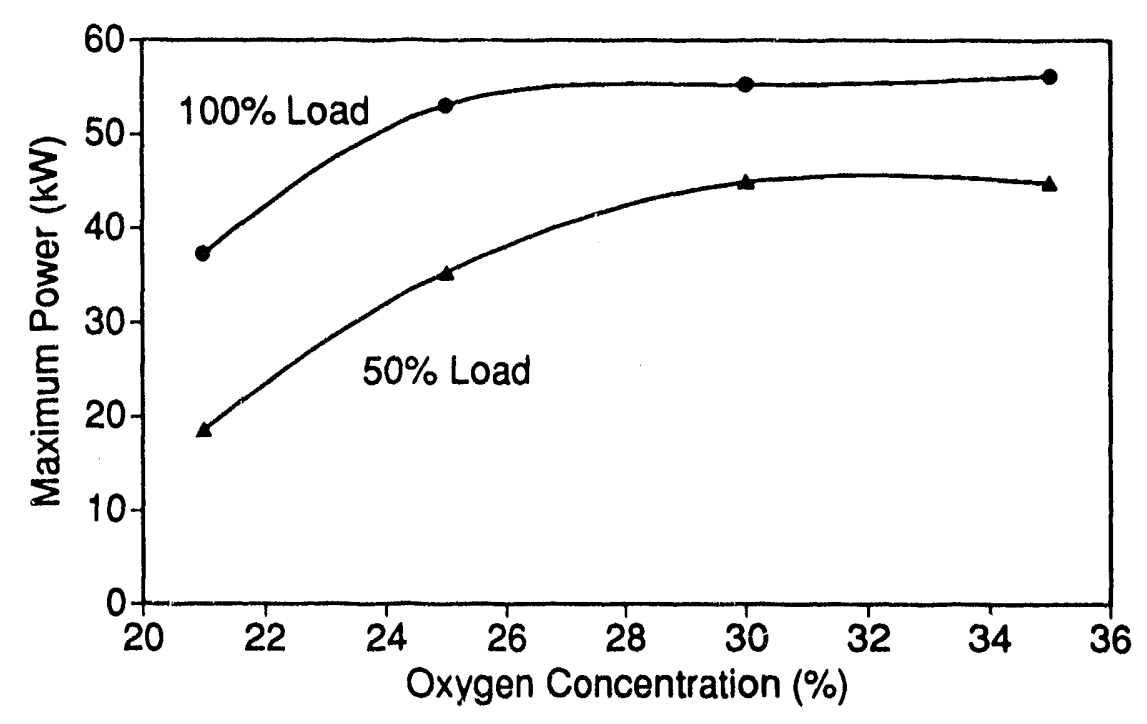

FIGURE 5 Maximum Attainable Power with No. 2 Diesel Fuel

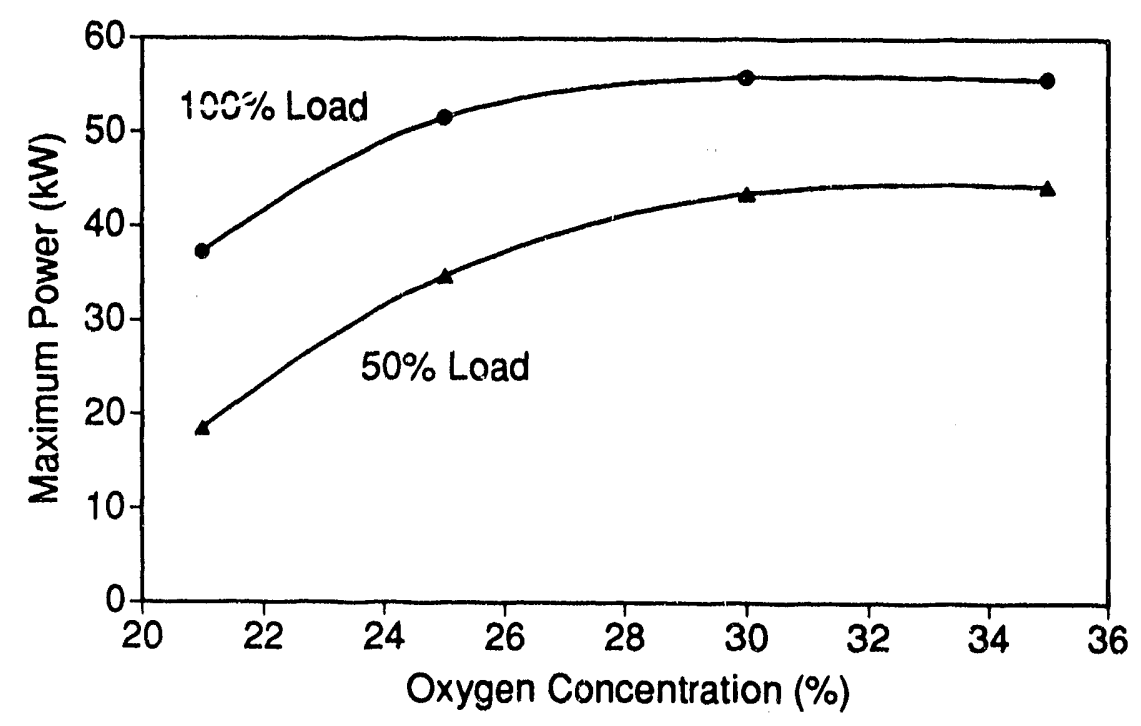

FIGURE 6 Maximum Attainable Power with No. 4 Diesel Fuel

Turbocharging cannot achieve this level of increase in power density because the resulting pressure ratio and peak cylinder pressures would be beyond the state-of-the-art diesel engines. The rise in peak cylinder pressures caused by oxygen enrichment is very nominal when compared with those of current engines in production (see Sec. 3.1.6).

\subsubsection{Thermal Efficiency}

Another commonly used indicator of engine performance is brake-specific fuel consumption, which is expressed as $\mathrm{g} /(\mathrm{kWh})$ or $\mathrm{lb} /(\mathrm{bhp} \cdot \mathrm{h})$. In this test series, the fuel quality 
varied considerably because of its water content, and the directly measured parameter was the mass-flow rate of test "fuel," including its water content. Hence, comparisons on the basis of bsfc could lead to confusing and misleading interpietations. To avoid such confusion, we use comparisons based on thermal efficiency, which takes into account the energy content of the test "fuel." The thermal efficiency is defined as follows:

$$
\eta=\frac{p}{\dot{m} * q}
$$

where:

$$
\begin{aligned}
\mathbf{p} & =\text { power output } \\
\eta & =\text { thermal efficiency } \\
\dot{\mathrm{m}} & =\text { mass-flow rate, and } \\
\mathbf{q} & =\text { energy per } \text { ınit mass of fuel. }
\end{aligned}
$$

The use of a consistent set of units is assumed in the calculation of thermal efficiency.

The test data show that the thermal efficiency is higher with No. 2 diesel fuel than with No. 4 diesel fuel. The higher efficiency could be attributed to the engine and its fuel injection systern, which were designed and fine-tuned to operate on No. 2 diesel fuel. Fuel atomization and spray pattern ane probably less than optimal with No. 4 fuel, although a detailed investigation of this possibility is beyond the scope of this project. Thermal efficiency consistenly increased with the addition of water up to about $5 \%$ of the fuel mass. The increase in thermal efficiency appears to be a fundamental thermodynamic phenomenon rather than a microexplosion phenomenon as reported by others ${ }^{15}$ ), because it was accurately predicted by a computer model that did not include microexplosions. Nevertheless, microexplosions might be exploited to enhance combustion efficiency in the future. The addition of more than $5 \%$ water typically results in a rapid decrease from the maximum thermal efficiency; however, with the addition of more than $8 \%$ water, thermal efficiency is generally lower than what it would be without the addition of water. Figure 7 shows an example of these effects at an $\mathrm{O}_{2}$ level of $25 \%$. In addition, the thermal efficiency was higher at a higher power output, as shown in Fig. 7.

At the fueling rate for constant power, the thermal efficiency initially increased with $\mathrm{O}_{2}$ concentration, but with further oxygen addition, it decreased. Thus, as more oxygen is pumped into the engine, it is necessary to make use of that oxygen by burning more fuel to produce more power (Fig. 8).

\subsubsection{Emissions of Nitrogen Oxide}

Emissions of nitrogen oxide are known to increase with increasing combustion temperatures. Because oxygen enrichment results in higher combustion and adiabatic flame temperatures, $\mathrm{NO}_{\mathrm{x}}$ emissions increase with oxygen enrichment. The presence of water reduces the 


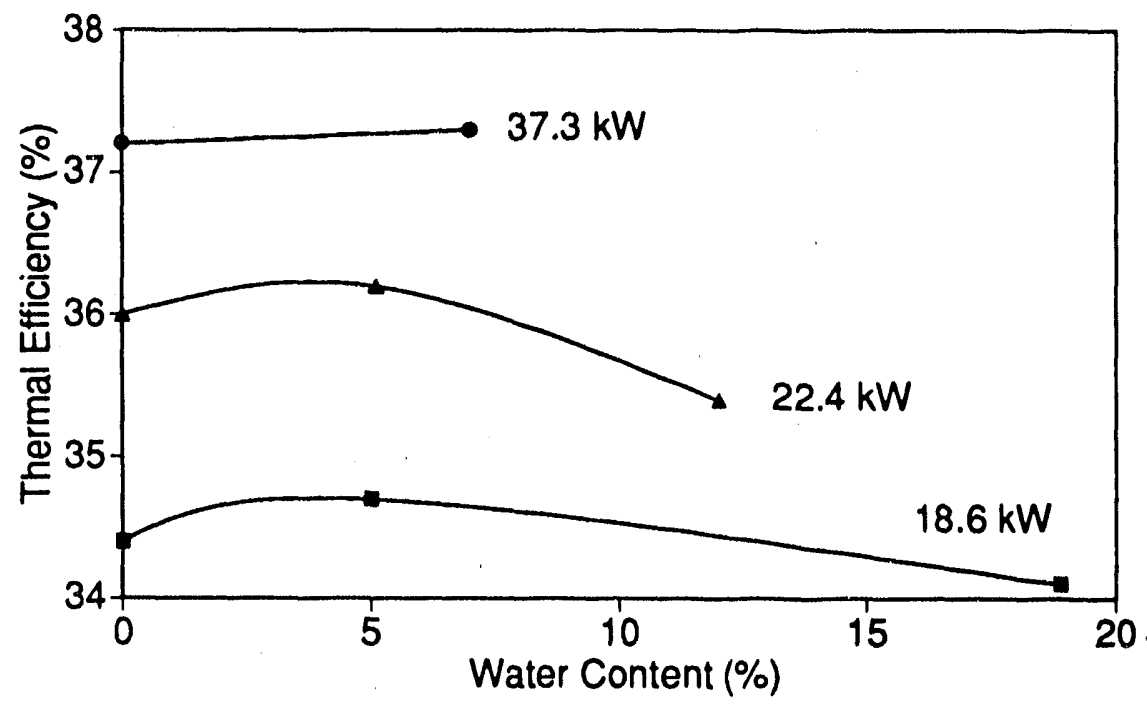

FIGURE 7 Effect of Water Content on Thermal Efficiency

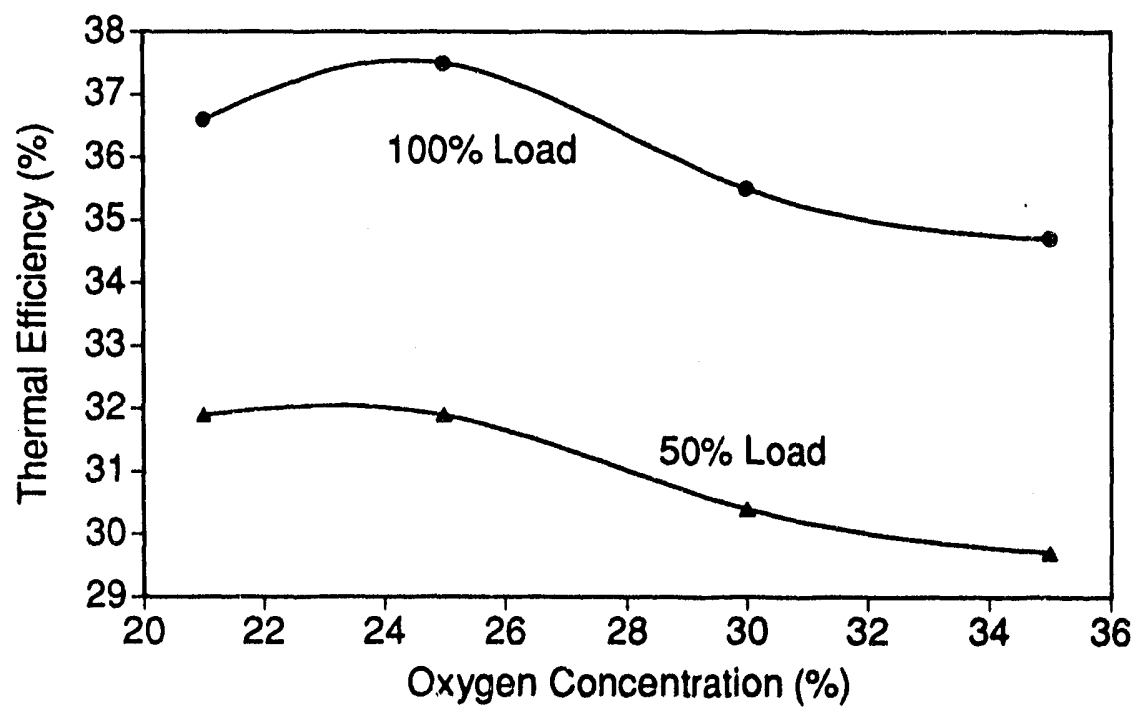

FIGURE 8 Effect of Oxygen on Thermal Efficiency

temperatures and, as a result, decreases $\mathrm{NO}_{\mathrm{x}}$ emissions. The engine test data presented in Fig. 9 confirm the decrease in $\mathrm{NO}_{\mathrm{x}}$ emissions. This finding is very encouraging because the major objection to the application of oxygen-enrichment technology has been the high level of $\mathrm{NO}_{\mathrm{x}}$ emissions. The data shown in Fig. 9, however, show that the brake-specific NO $_{x}$ emissions at $25 \%$ oxygen could be returned to the base level when the fuel contains about $20 \%$ water. This technique, combined with other established $\mathrm{NO}_{\mathrm{x}}$-reduction methods (such as retarded injection timing), appears to be promising for the control of the overall $\mathrm{NO}_{\mathrm{x}}$ emissions from a diesel engine with oxygen-enriched combustion air. 
A similar trend was not observed, however, when No. 4 diesel fuel emulsions were used and the engine was run at the constant power fueling rate, as shown in Fig. 10. However, as illustrated in Fig. 11, the effect of an increase in power output is a decrease in the brake-specific $\mathrm{NO}_{\mathrm{x}}$ level with either base fuel. This finding again confirms the earlier conclusion that these two technologies work well with a diesel engine only if the engine output is increased to the maximum level, the limiting factor being the exhaust temperature.

\subsubsection{Particulate-Matter Emissions and Smoke}

The test engine appears to be designed for low levels of particulate-matter emissions. Hence, there was not much room for improvements in mass particulate-matter emissions as oxygen levels were increased. The particulate-matter emissions with No. 4 diesel fuel were consistently higher than those with No. 2 diesel fuel (see Fig. 12 for a constant power fueling rate). As noted before, the higher emissions may be attributed to the suboptimal atomization and spray pattorn caused by the use of the more viscous fuel. Figure 13 shows the importance of increasing the engine output with an increased level of oxygen.

The general tendency of particulate-matter emissions to increase with water content level in the fuel is shown in Fig. 14. However, other data indicated considerable scatter, depending on the base fuel, oxygen level, engine load conditions, and water content. Figure 14 also indicates the importance of a higher level of power output with oxygen enrichment and emulsification of fuel with water. If the fueling rate (i.e., the power output level) is not increased with increasing oxygen enrichment, particulate-matter emissions could, in fact, increase. The level of exhaust

$\rightarrow 35 \% \mathrm{O}_{2} \rightarrow 30 \% \mathrm{O}_{2} \rightarrow 25 \% \mathrm{O}_{2} \rightarrow 21 \% \mathrm{O}_{2}$

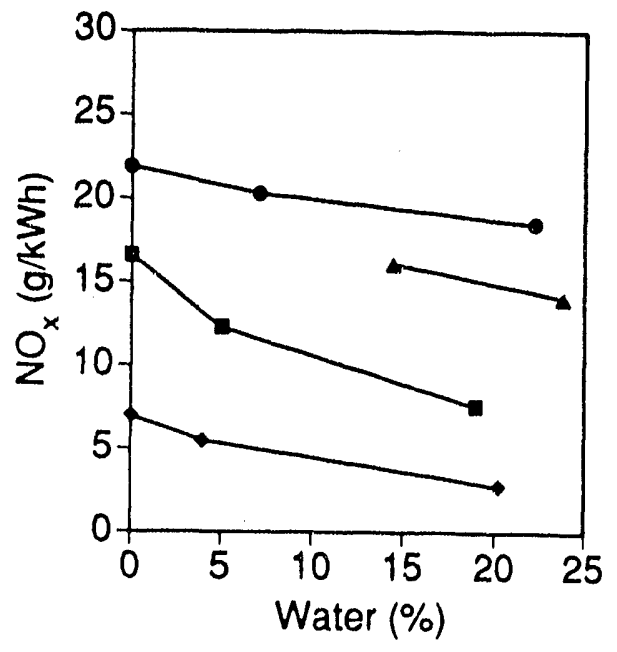

FIGURE 9 Effect of Water and Oxygen on $\mathrm{NO}_{x}$ Emissions, No. 2 Diesel Fuel

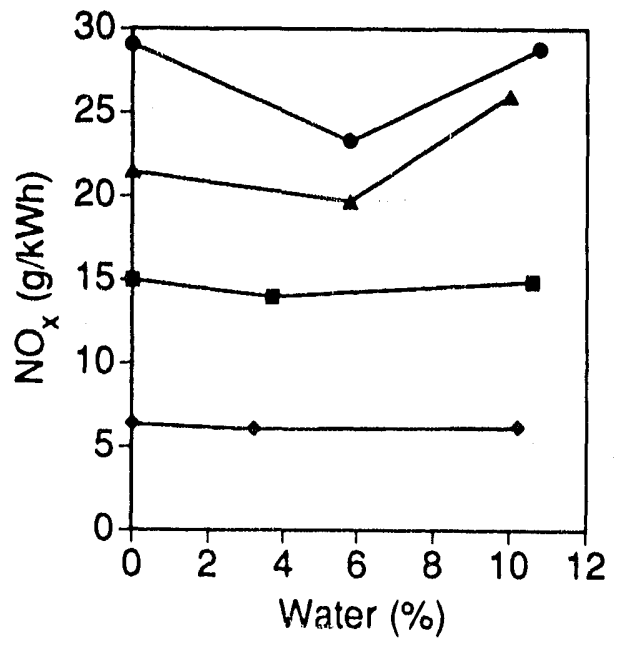

FIGURE 10 Effect of Water and Oxygen on $\mathrm{NO}_{x}$ Emissions, No. 4 Diesel Fuel 


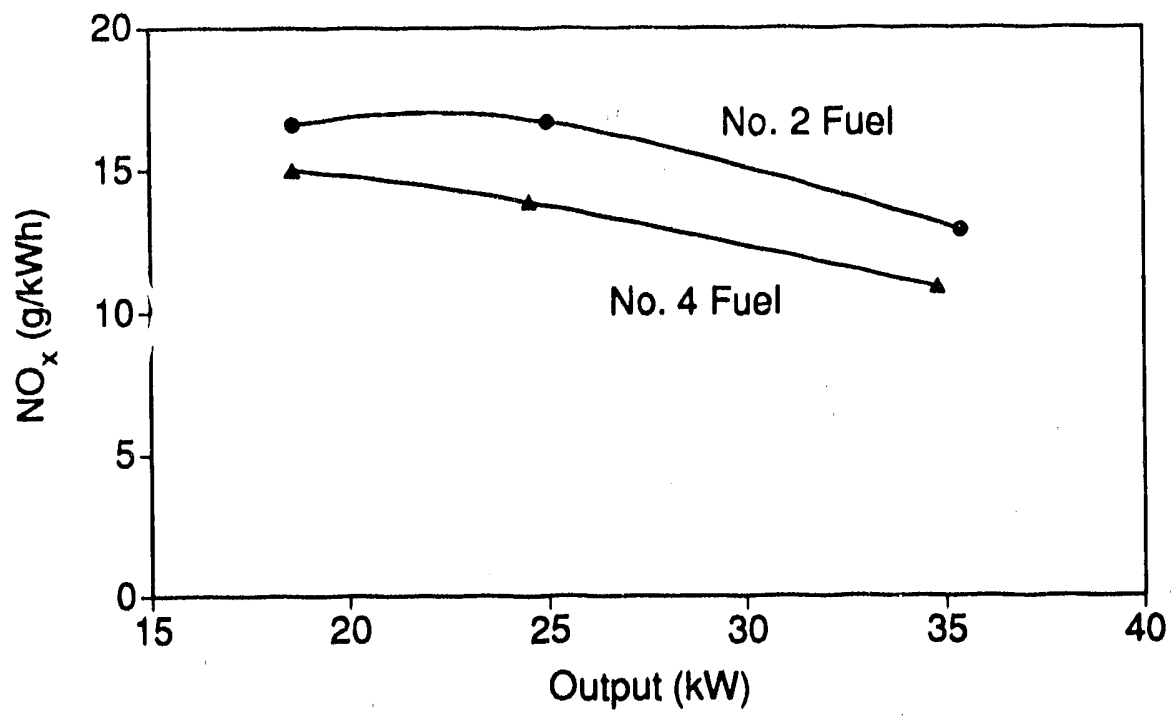

FIGURE 11 Effect of Power on $\mathrm{NO}_{x}$ Emissions

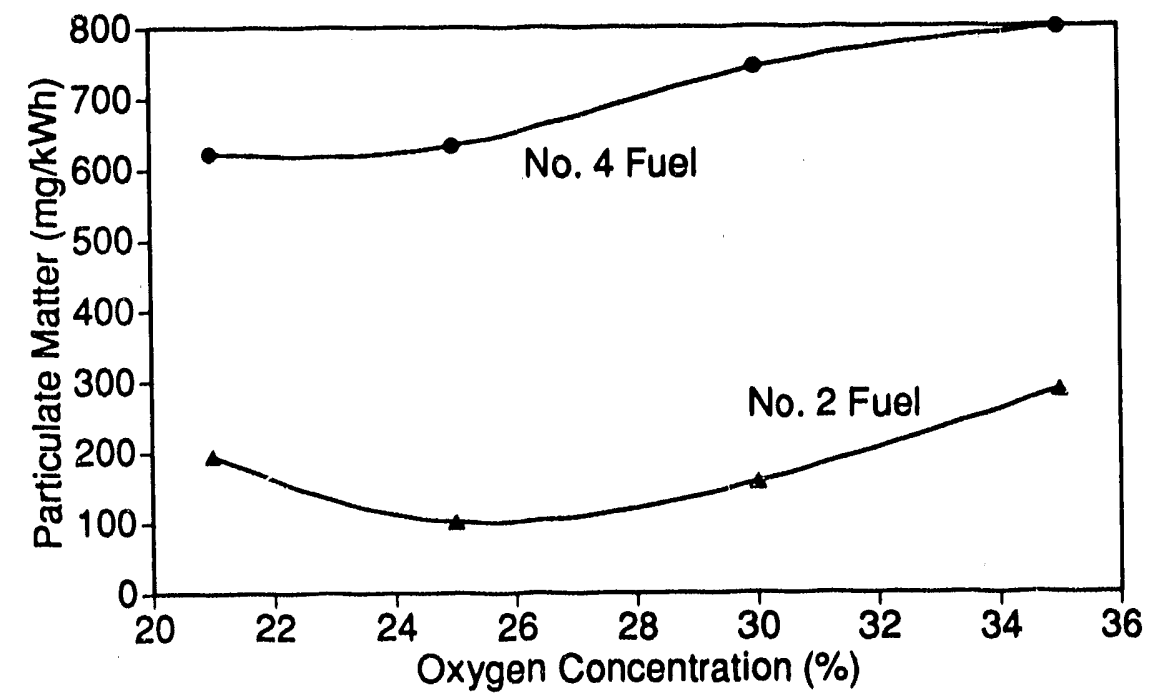

FIGURE 12 Effect of Oxygen on Particulate-Matter Emissions 


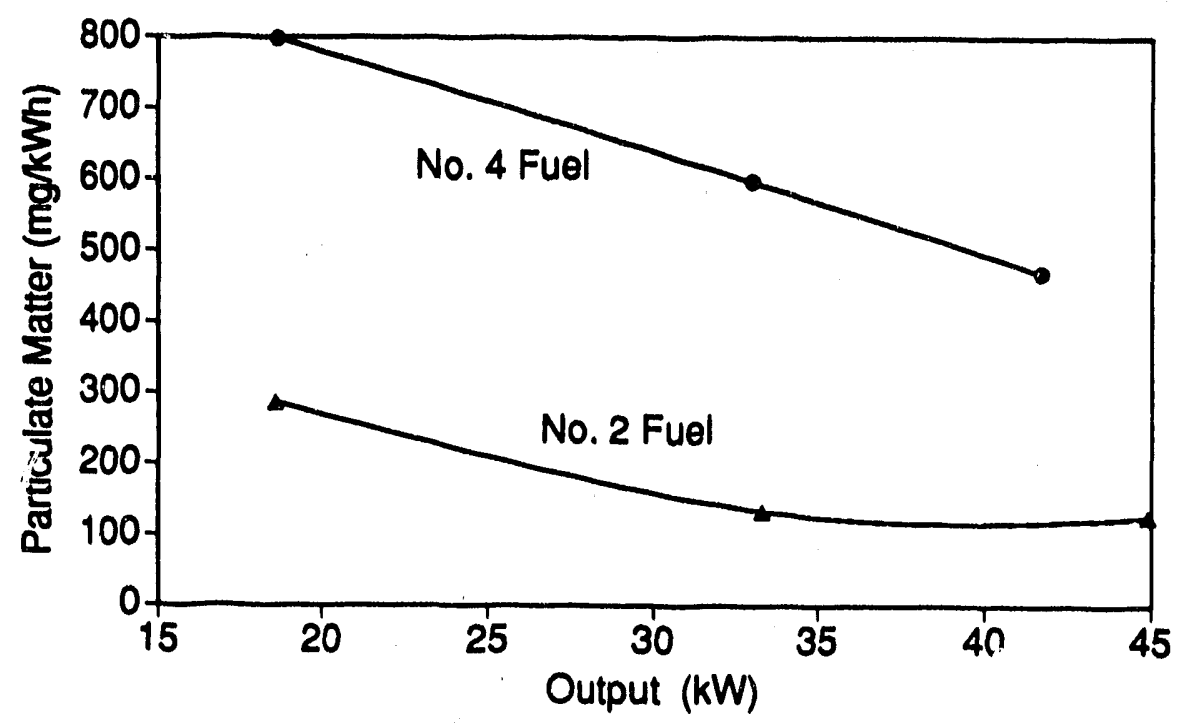

FIGURE 13 Effect oi Power on Particulate-Matter Emissions

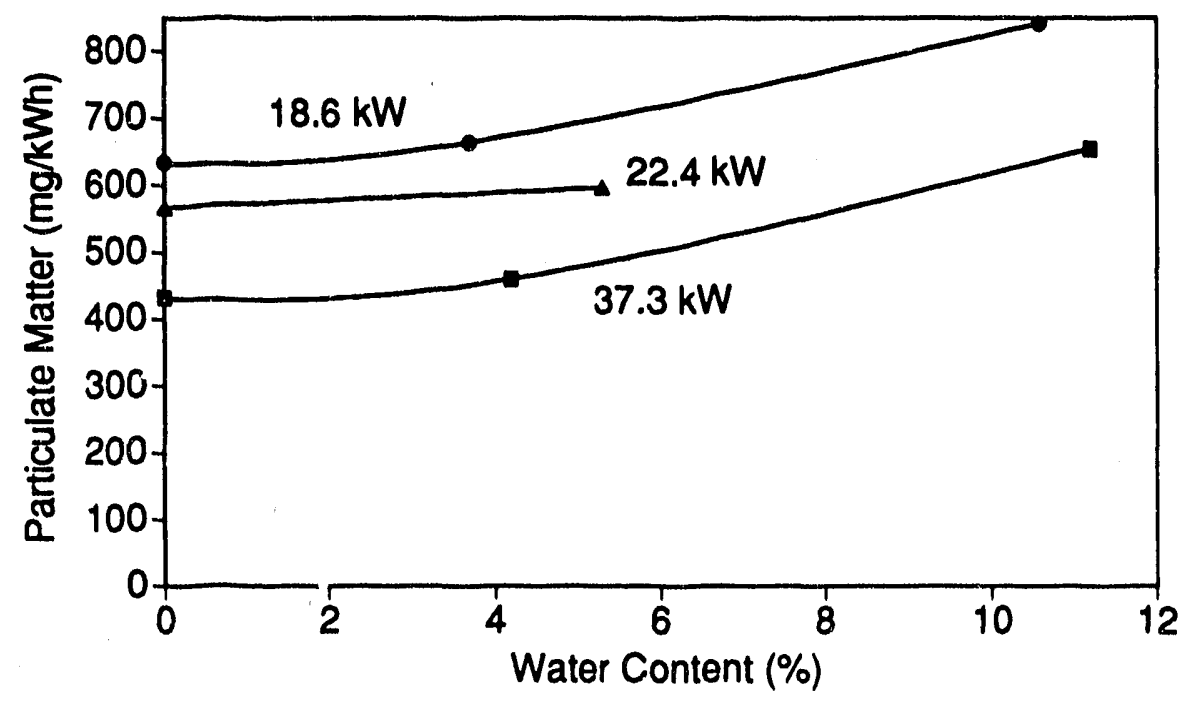

FIGURE 14 Effect of Water Content on Particulate-Matter Emissions 
smoke, a different type of measurement than particulate-matter emissions, always decreased when the oxygen level in the intake was increased. The degree of oxygen concentration did not make any measurable difference in the level of smoke, which was already low at $25 \% \mathrm{O}_{2}$. This trend was observed with both base fuels and with their emulsions included in the test matrix, which results in a major departure in the way in which diesel engines are generally rated. The rated power would not be smoke-limited when oxygen-enrichicd air is used; rather, power would be limited by the gas temperatures that the materials could withstand. If high-temperature materials could be employed cost-effectively, the next limiting parameter would be the cylinder pressures. When the data analysis was completed, the particulate-matter data showed considerable scatter and the repeatability was poor, even though the smoke data were consistent and reproducible. Hence, the particulate-matter data should be used for trends rather than for absolute values.

\subsubsection{Ignition Delay}

Ignition delay is the interval between the injection of fuel into the cylinder and the start of energy release caused by comburtion. Previous research has indicated that oxygen enrichment woul 1 reduce ignition delay. 5,8 Figure 15 illustrates the effect of power output and intake oxygen level on ignition delay. A reduction in ignition delay of $4 \mathrm{deg}$. crank angle was observed when the intake $\mathrm{O}_{2}$ level was increased to $35 \%$. Moreover, as the engine power output was increased to make use of the excess oxygen, the ignition delay was further reduced. This reduction in ignition delay is important because it allows for the retardation of injection timing without any degradation of engine performance. Retarding the injection timing is a commonly used method of decreasing $\mathrm{NO}_{\mathrm{x}}$ emissions from diesel engines. Because the increase in $\mathrm{NO}_{\mathrm{x}}$ with enriched oxygen has been well documented, 4,10 a specific means of controlling the same is needed.

In this project, water was introduced into the combustion process in the form of emulsified fuel. The presence of water in fuel tends to increase the ignition delay. Figure 16 shows the experimental ignition delay when the amount of water in the fuel was changed. A combination of a small amount of water in the fuel and oxygen-enriched air for combustion resulted in a net reduction in ignition delay of 3-4 deg. crank angle. Figure 17 shows a comparison of the ignition delays when the base fuel was changed from No. 2 to No. 4 diesel fuel. The less-refined No. 4 fuel consistently had higher ignition delay. This finding indicates the need for developing a combustion system specifically for low-grade fuels.

\subsubsection{Cylinder Pressures}

Higher oxygen levels and power levels increase peak cylinder pressures, as shown in Fig. 18. Neveriheless, the magnitude of the increase in peak pressure is less than $15 \%$, even with a power increase of $50 \%$. State-of-the-art diesel engines could easily withstand the increased pressures. Water in the fuel tends to decrease and low-grade fuel tends to increase the peak pressures, as shown in Fig. 19. 


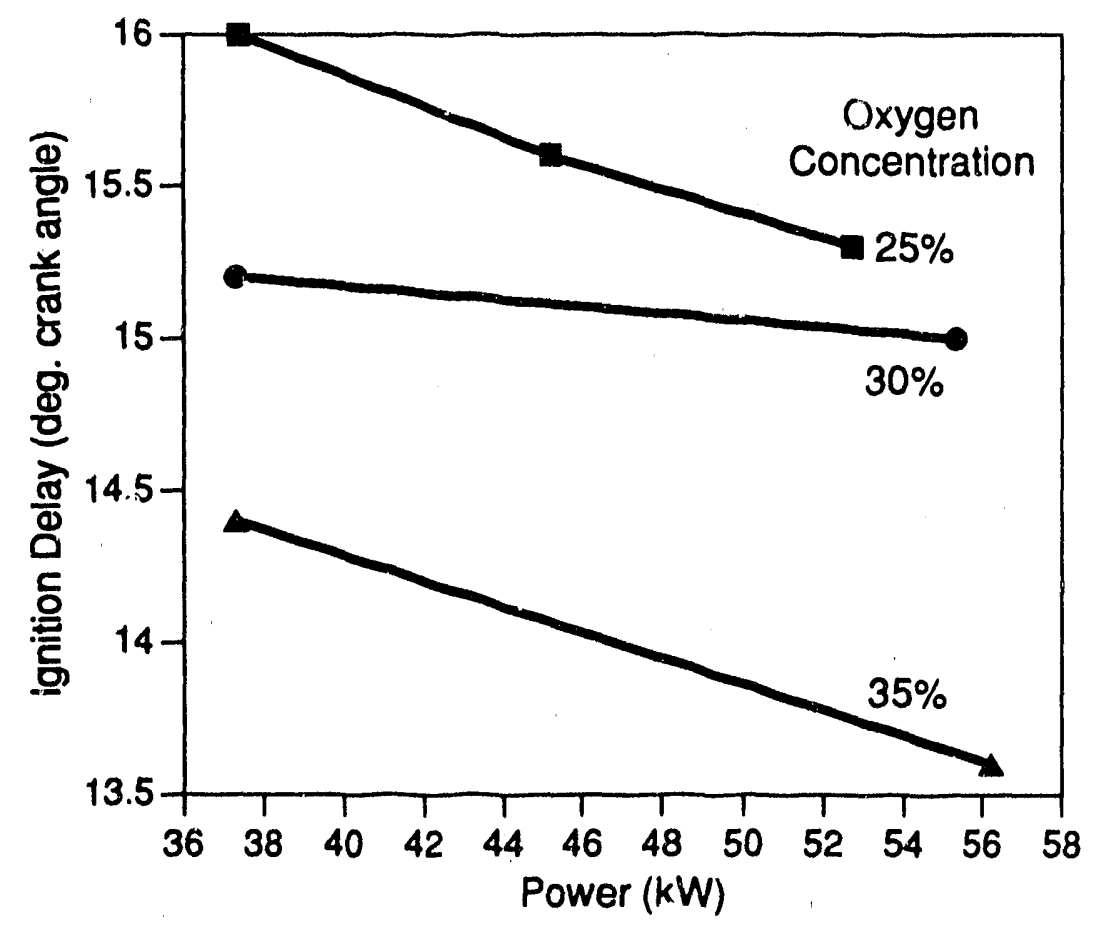

FIGURE 15 Effect of Power Output and Oxygen Level on Ignition Delay (No. 2 diesel fuel, $100 \%$ load, no water; baseline ignition delay $=19$ deg.)

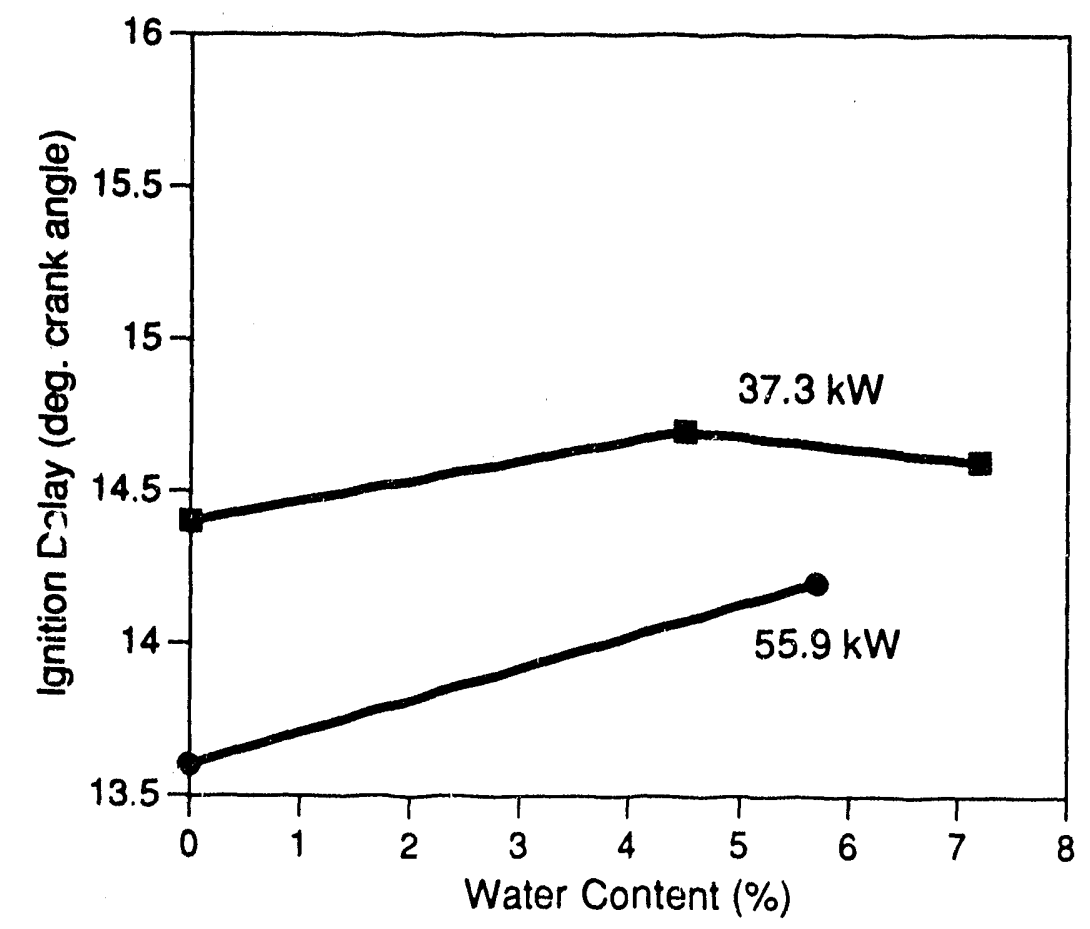

FIGURE 16 Effect of Water Content in the Fuel and Power Output on Ignition Delay (No. 2 diesel fuel, $100 \%$ load, $35 \% \mathrm{O}_{2}$; baseline ignition delay $=19 \mathrm{deg}$.) 


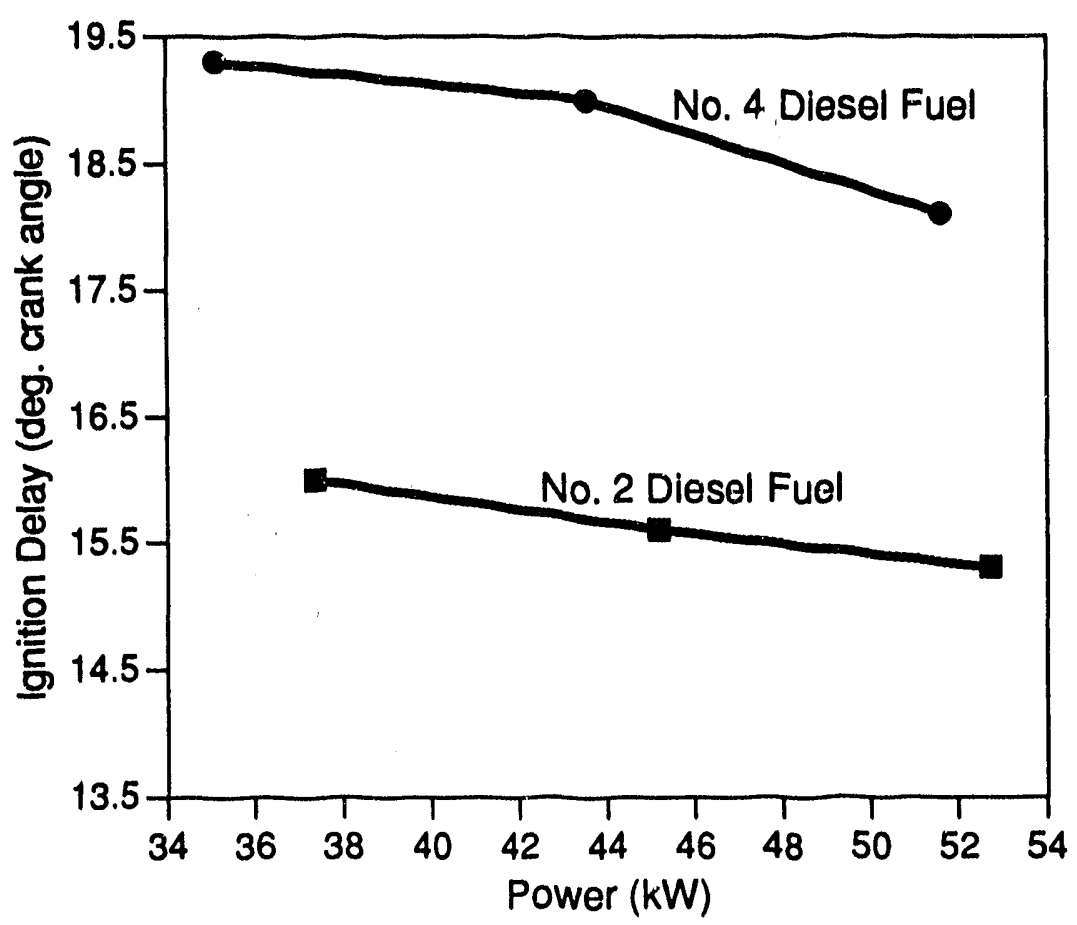

FIGURE 17 Effect of Using Less-Refined Fuel on Ignition Delay ( $100 \%$ load, no water, $25 \% \mathrm{O}_{2}$ )

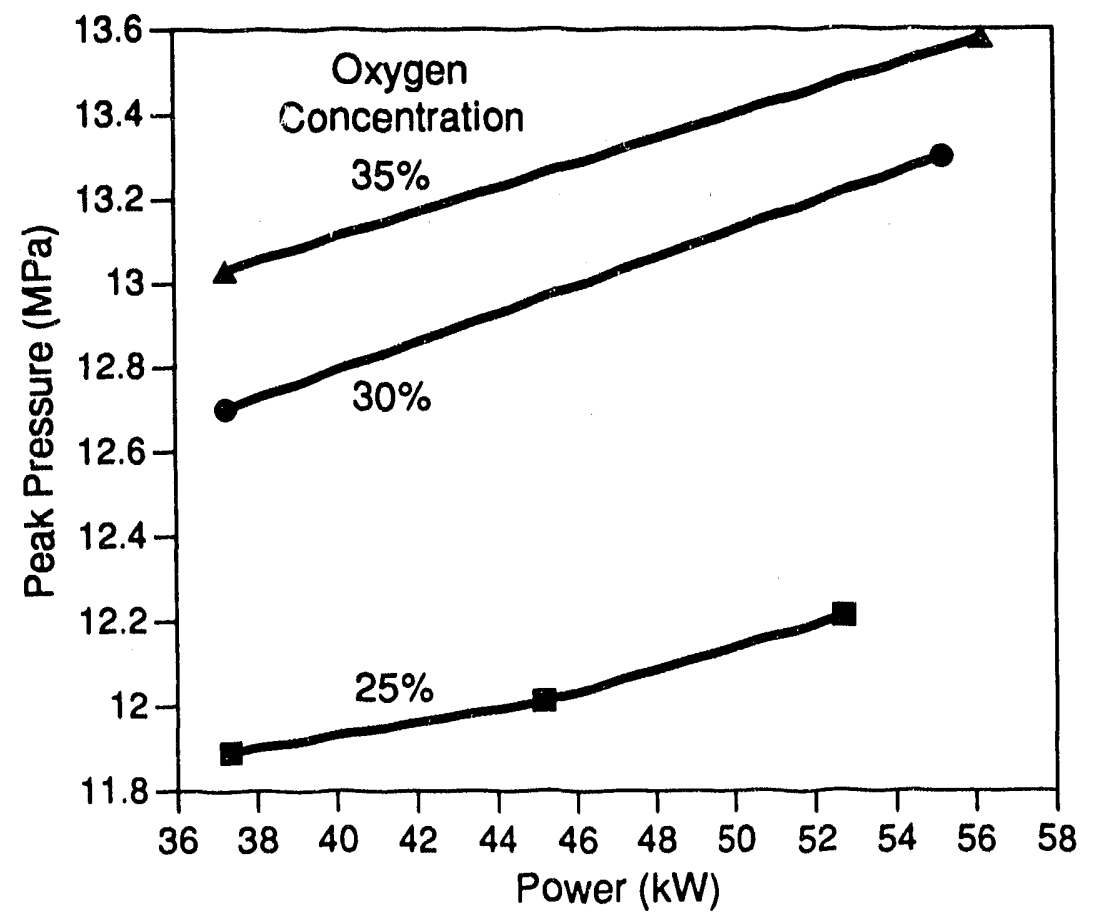

FIGURE 18 Effect of Power Output and Oxygen Level on Peak Cylinder Pressure (No. 2 diesel fuel, $100 \%$ load, no water; baseline peak pressure $=11.3 \mathrm{MPa}$ ) 


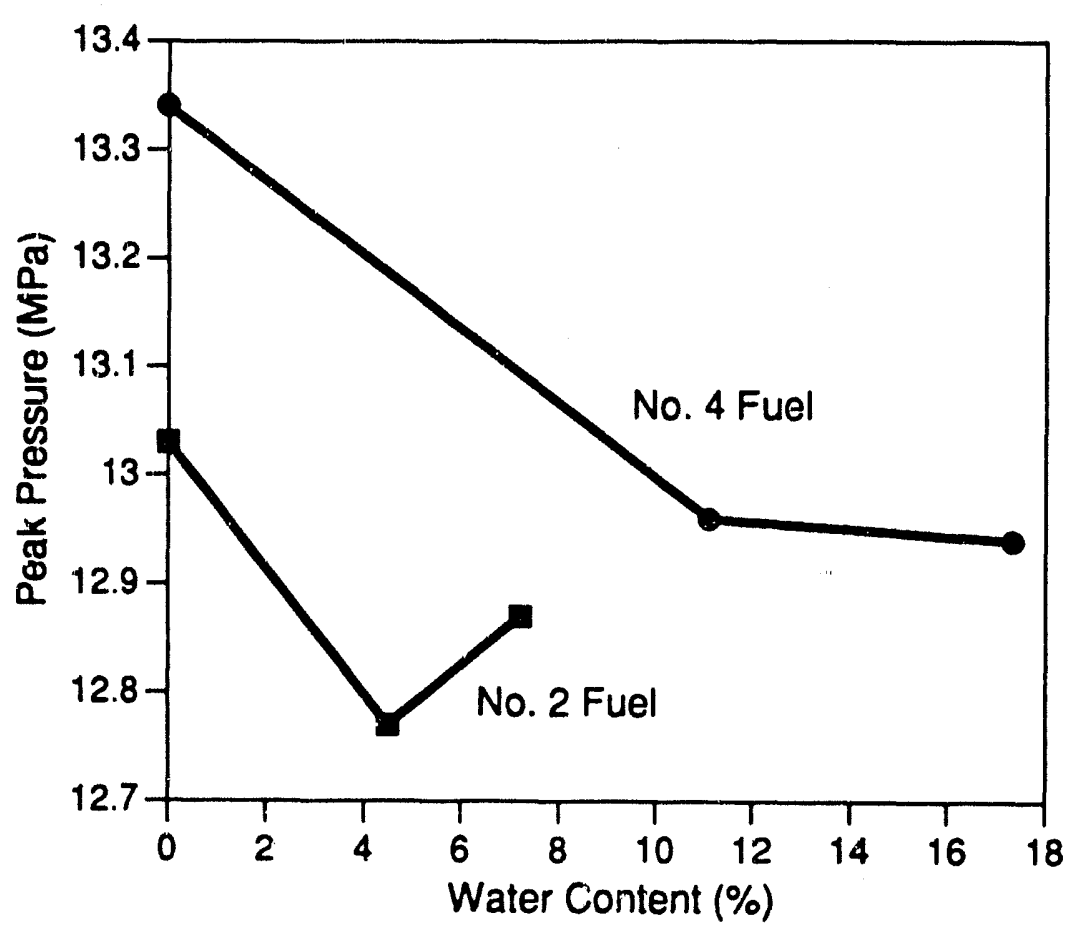

FigURE 19 Comparison of Peak Cylinder Pressures with No. 2 and No. 4 Diesel Fuels $\left(100 \%\right.$ bad, $37.3 \mathrm{~kW}, 35 \% \mathrm{O}_{2}$; baseline peak pressure $=11.3 \mathrm{MPa}$ )

The 30-cycle-average cylinder pressure diagrams were smoothed by progressively averaging three points before and three points after each crank angle. The difference in the pressure diagrams due to intake oxygen level is illustrated in Fig. 20. For both curves, the fueling rate was chosen to give power output of $37.3 \mathrm{~kW}$ (100\% load). Because the differences are not large, only the two extreme oxygen levels, $21 \%$ and $35 \%$, are shown.

Figure 21 shows the rates of pressure rise, dp/dQ, for $21 \%$ and $35 \%$ oxygen levels in an expanded scale for the beginning part of combustion. (These are the same runs as those shown in Fig. 20.) The combined effects of water in the fuel, oxygen-enriched air, and increasec power level on the cylinder pressure diagram are illustrated in Fig. 22. In this figure, run \#37 is the base case, whereas run \#100 includes the data for the $35 \%$ oxygen, $6.9 \%$ water in the fuel, and the maximum power (a 50\% increase from the base case) condition. It is clear that there is a net increase in $\mathrm{dp} / \mathrm{dQ}$ and a $17 \%$ increase in peak pressure. The cylinder pressure levels, however, are well within the current design limits of a diesel engine.

Figure 23 is a comparison of the cylinder pressure traces, and Fig. 24 is a comparison of the rate of pressure rise for No. 2 and No. 4 fuels. When lower-grade fuel is used, the pressure levels are somewhat higher and combustion starts later. 


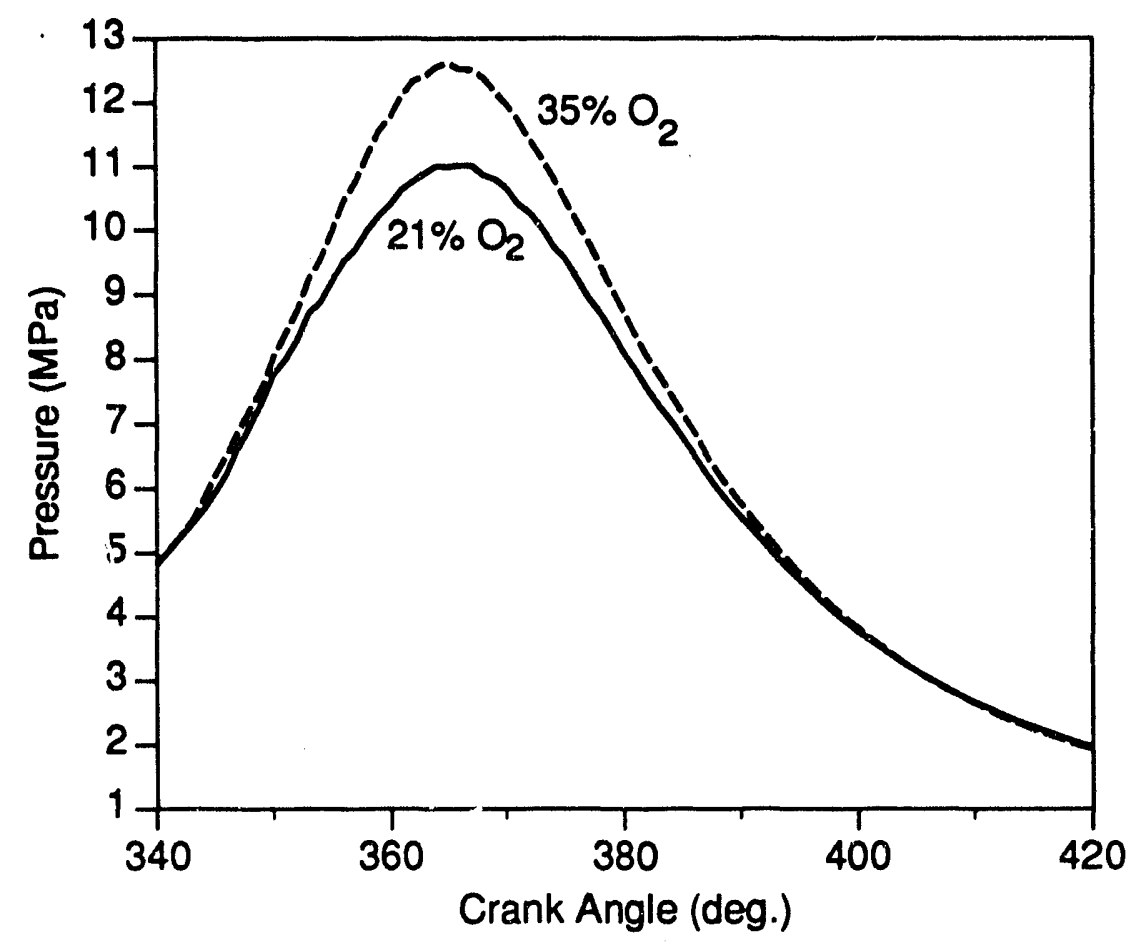

FIGURE 20 Effect of Intake Oxygen Levels on Cylinder Pressure (No. 2 fuel, $100 \%$ load, $37.3 \mathrm{~kW}$, no water)

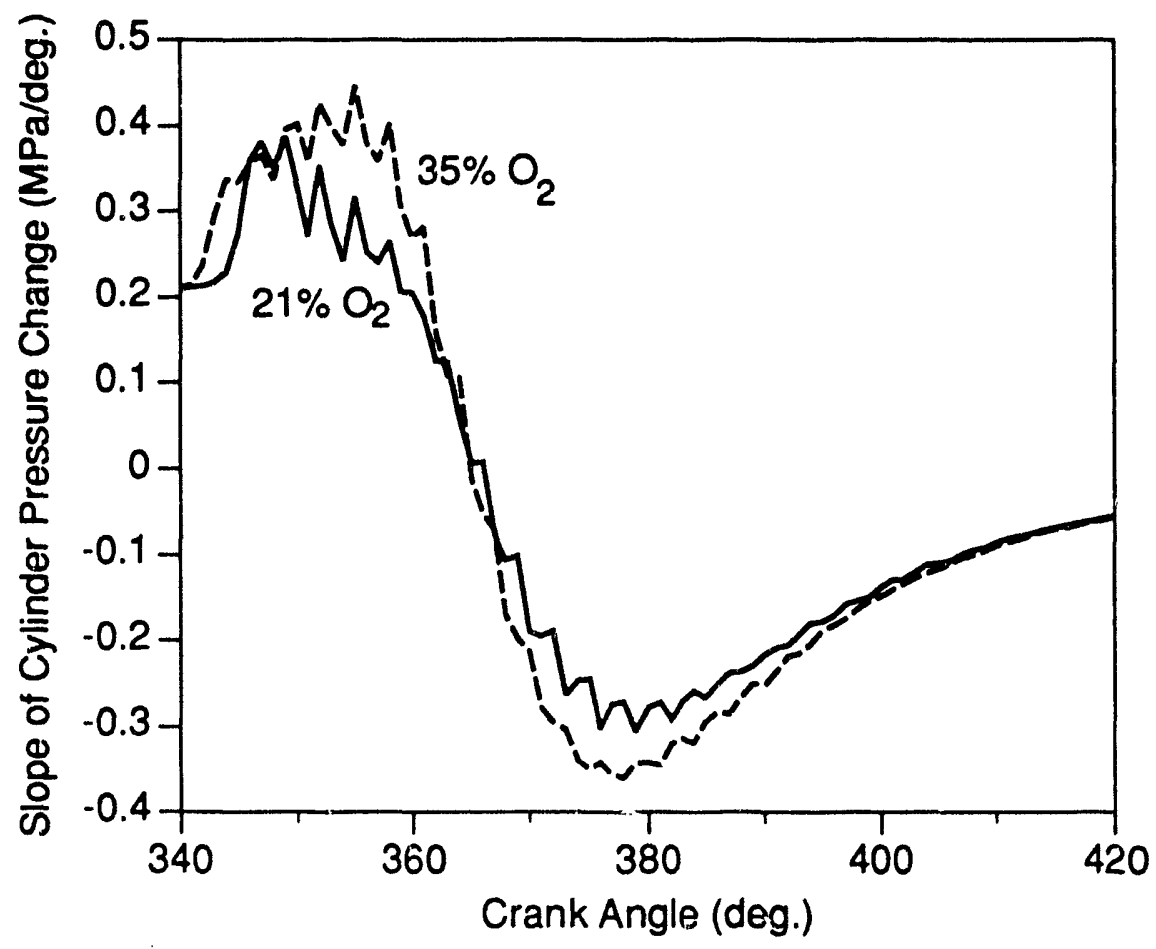

FIGURE 21 EffEct of Intake Oxygen Levels on Rates of Cylinder Pressure Rise (No. 2 fuel, $100 \%$ load, 37.3 kW, no water) 


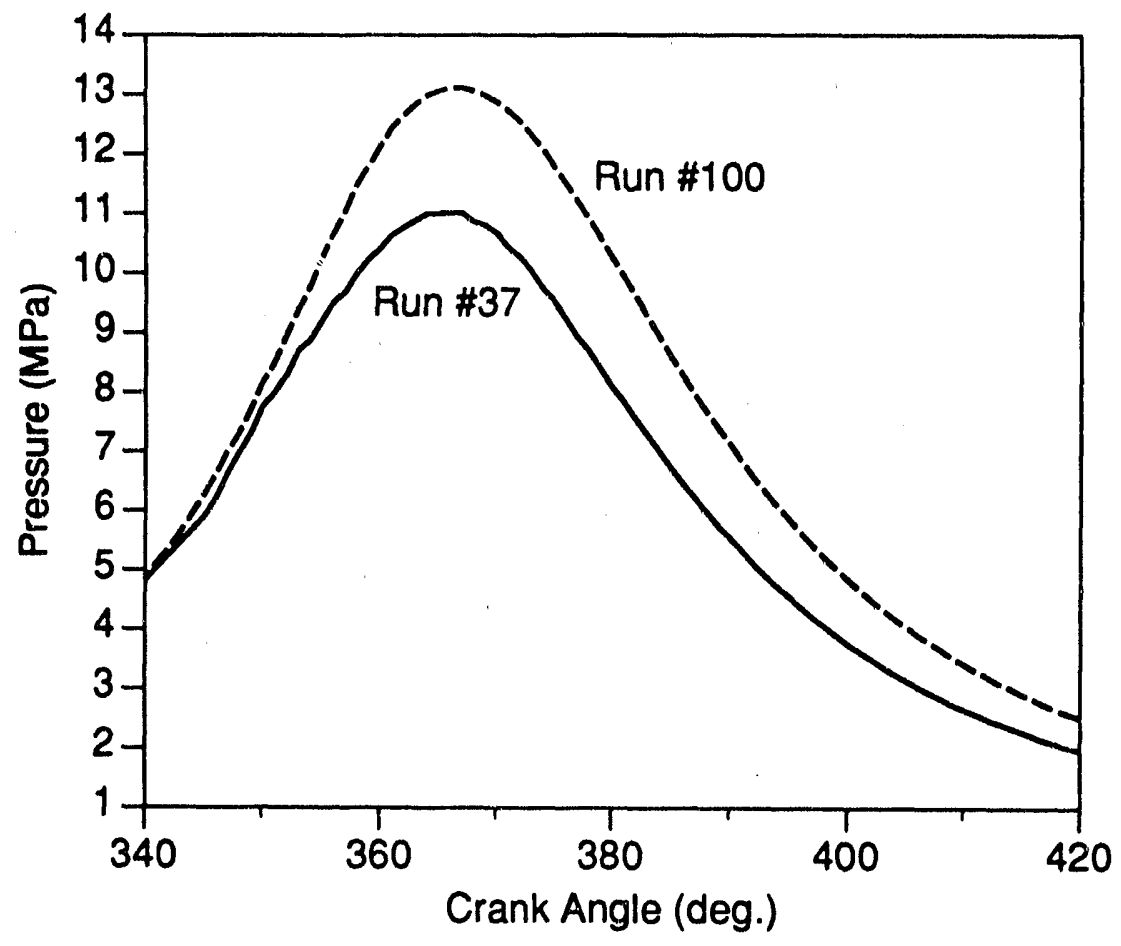

FIGURE 22 Effect of Water in the Fuels, Increased Oxygen in the Intake Air, and Increased Power Level on Cylinder Pressure (No. 2 fuel, 100\% load; $\# 370 \%$ water, $21 \% \mathrm{O}_{2}, 37.3 \mathrm{~kW} ; \# 1006.9 \%$ water, $35 \% \mathrm{O}_{2}$, $56 \mathrm{~kW}$ )

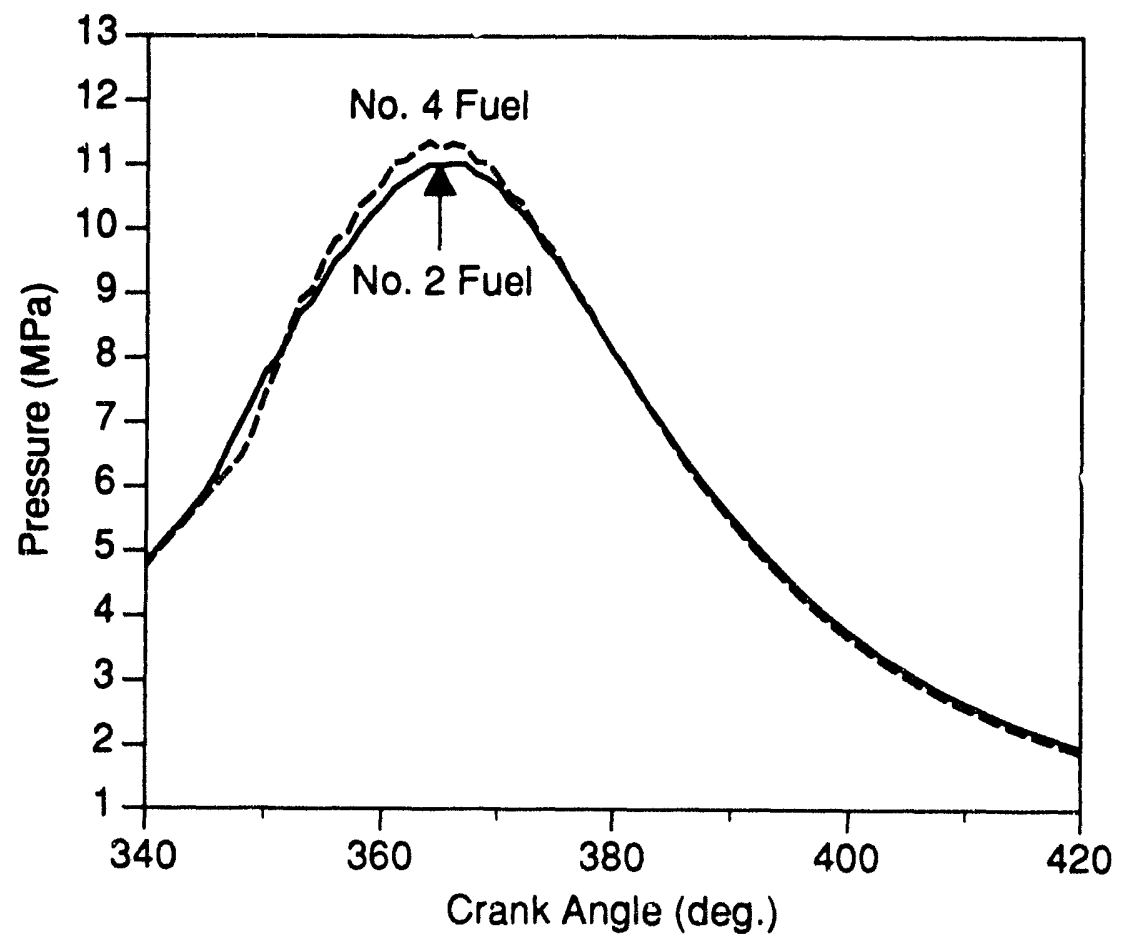

FIGURE 23 Comparison of Cylinder Pressures with No. 2 and No. 4 Diesel Fuels ( $100 \%$ bad, $37.3 \mathrm{~kW}, 21 \% \mathrm{O}_{2}$, no water) 


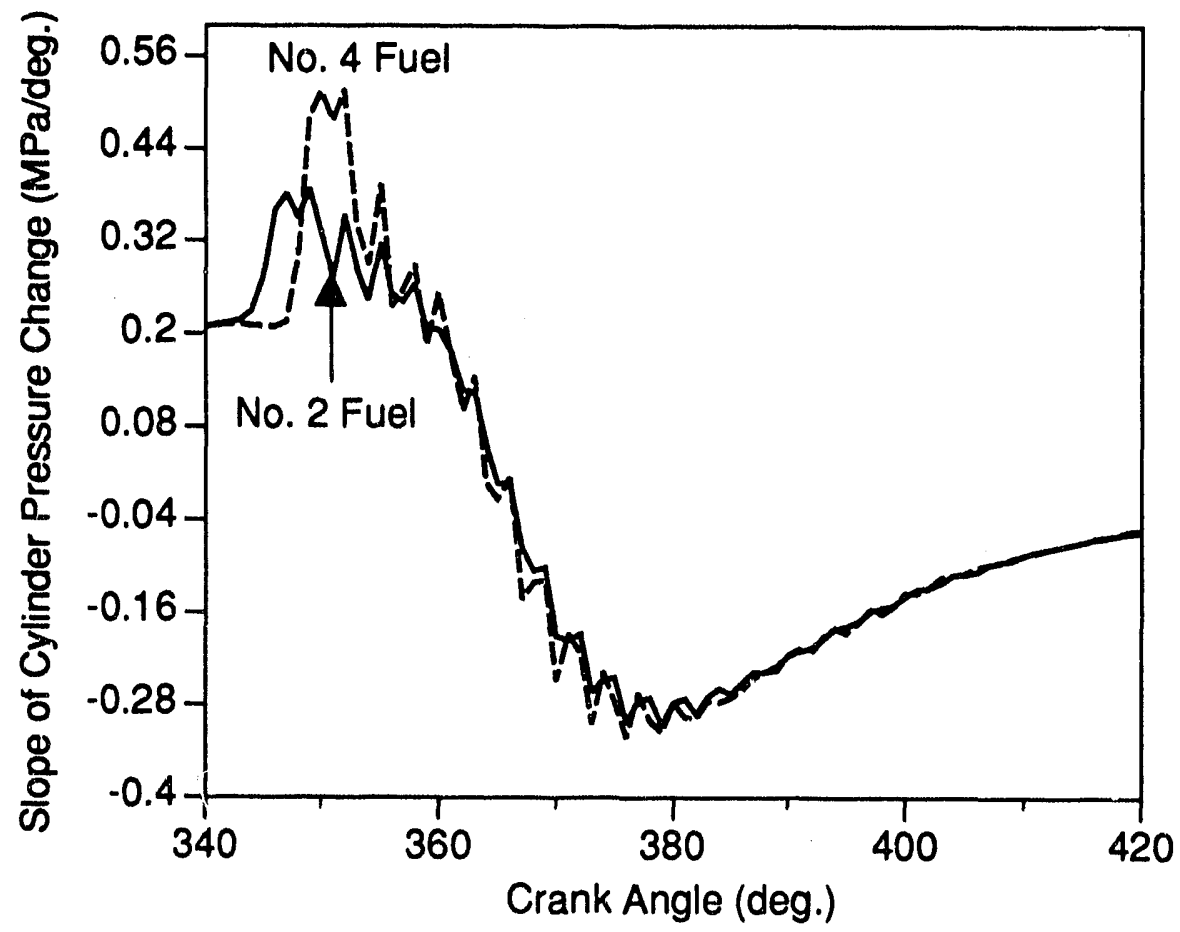

FIGURE 24 Comparison Rates of Pressure Rise with No. 2 and No. 4 Diesel Fuels ( $100 \%$ load, $37.3 \mathrm{~kW}, 21 \% \mathrm{O}_{2}$, no water)

\subsubsection{Heat-Release Rates}

From the experimental cylinder pressure diagrams, apparent rates of heat release were calculated by using a PC-based code. The purpose of the calculation was to identify overall trends and effects on combustion attributable to intake oxygen level, the amount of water in the fuel-water emulsion, and the power output. The combustion chamber of the engine was designed and finetuned for standard No. 2 diesel fuel and $21 \%$ oxygen in the intake air, however, for other fuels, emulsions, and oxygen levels, the design of the combustion chamber must be specifically optimized. The heat-release comparisons presented here could be used as a starting point for more detailed combustion studies and engine development incorporating these technologies.

Figure 25 presents the cumulative rate of burning for the same cases discussed earlier. The most obvious trend is that more of the energy release occurs in the earlier part of the combustion cycle when a higher level of oxygen is available. The changes in ignition delay discussed earlier are evident in Fig. 25, and the effects of water content in the fuel on heat-release rates are shown in Fig. 26. When water is present in the fuel, combustion starts a little later, but the rate of burning is measurably higher in the early part of combustion. This phenomenon might be caused by "micro explosion" phenomenon proposed by other investigators. 12 Figure 27 is a comparison of the cumulative heat-release diagrams of No. 2 and No. 4 diesel fuels. Number 4 fuel has a longer ignition delay, but it releases a larger fraction of its energy earlier in the combustion cycle than does No. 2 fuel. 


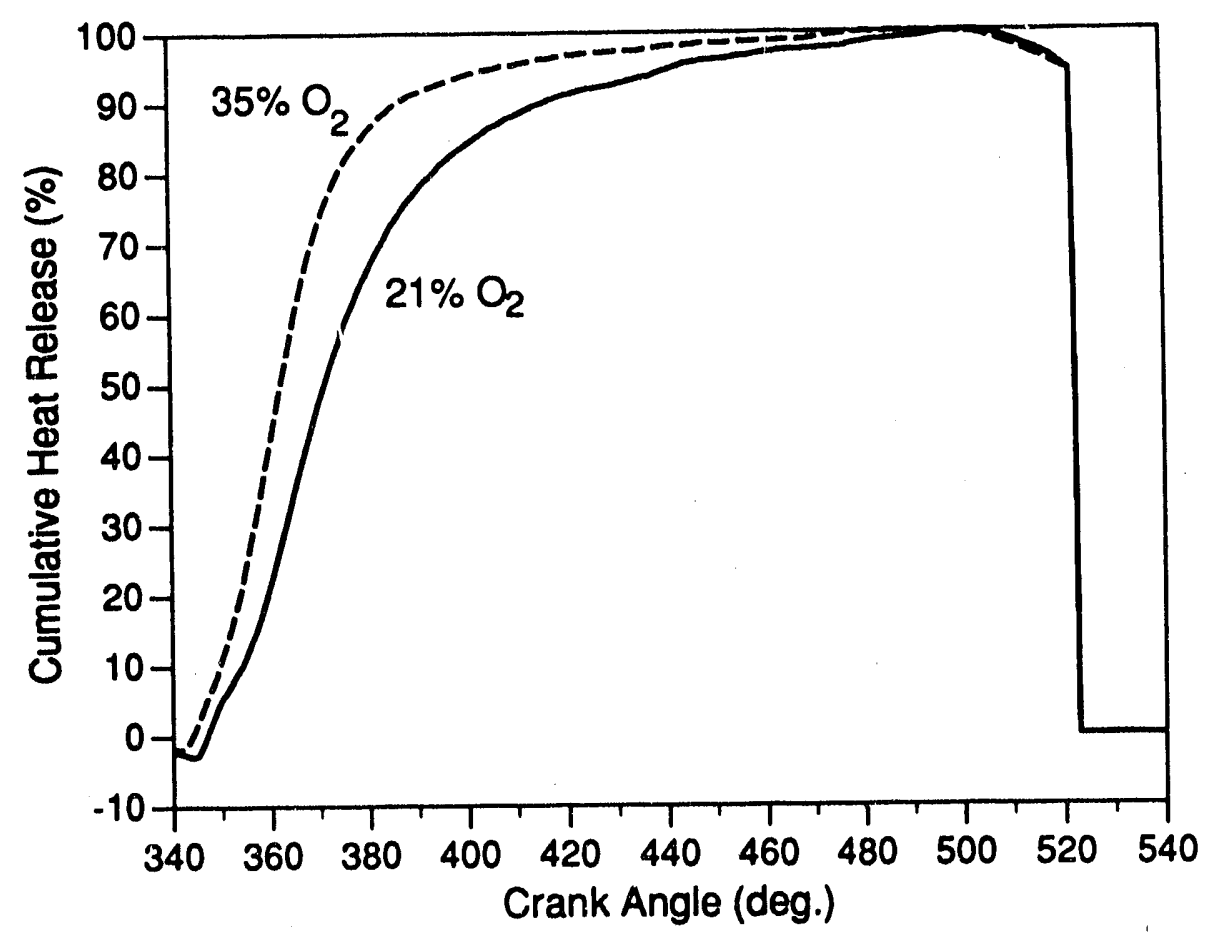

FIGURE 25 Effect of Oxygen on Cumulative Heat-Release Rates (No. 2 fuel, $100 \%$ load, $37.3 \mathrm{~kW}$, no water)

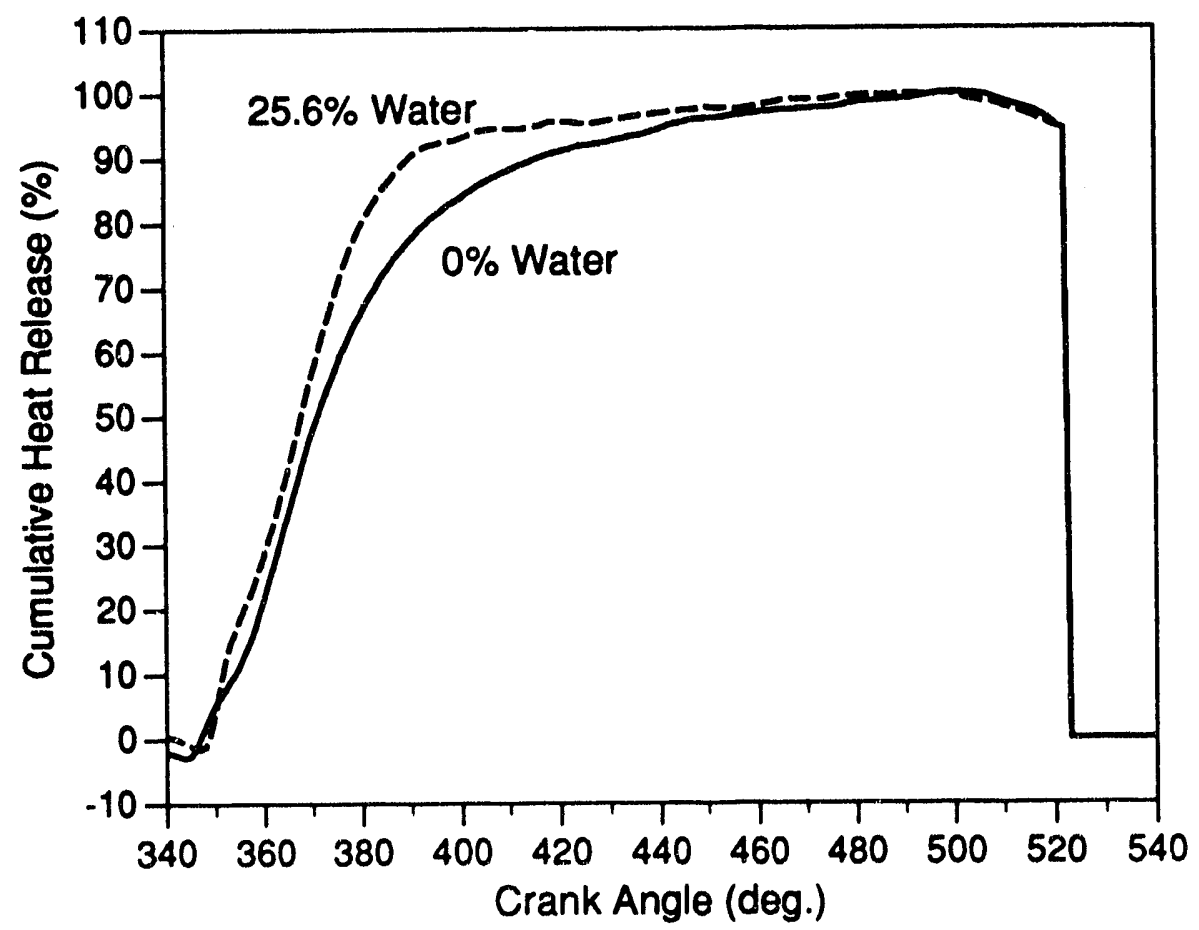

FIGURE 26 Effect of Water on Cumulative Heat-Release Rates (No. 2 fuel, $100 \%$ load, $37.3 \mathrm{~kW}, 21 \% \mathrm{O}_{2}$ ) 


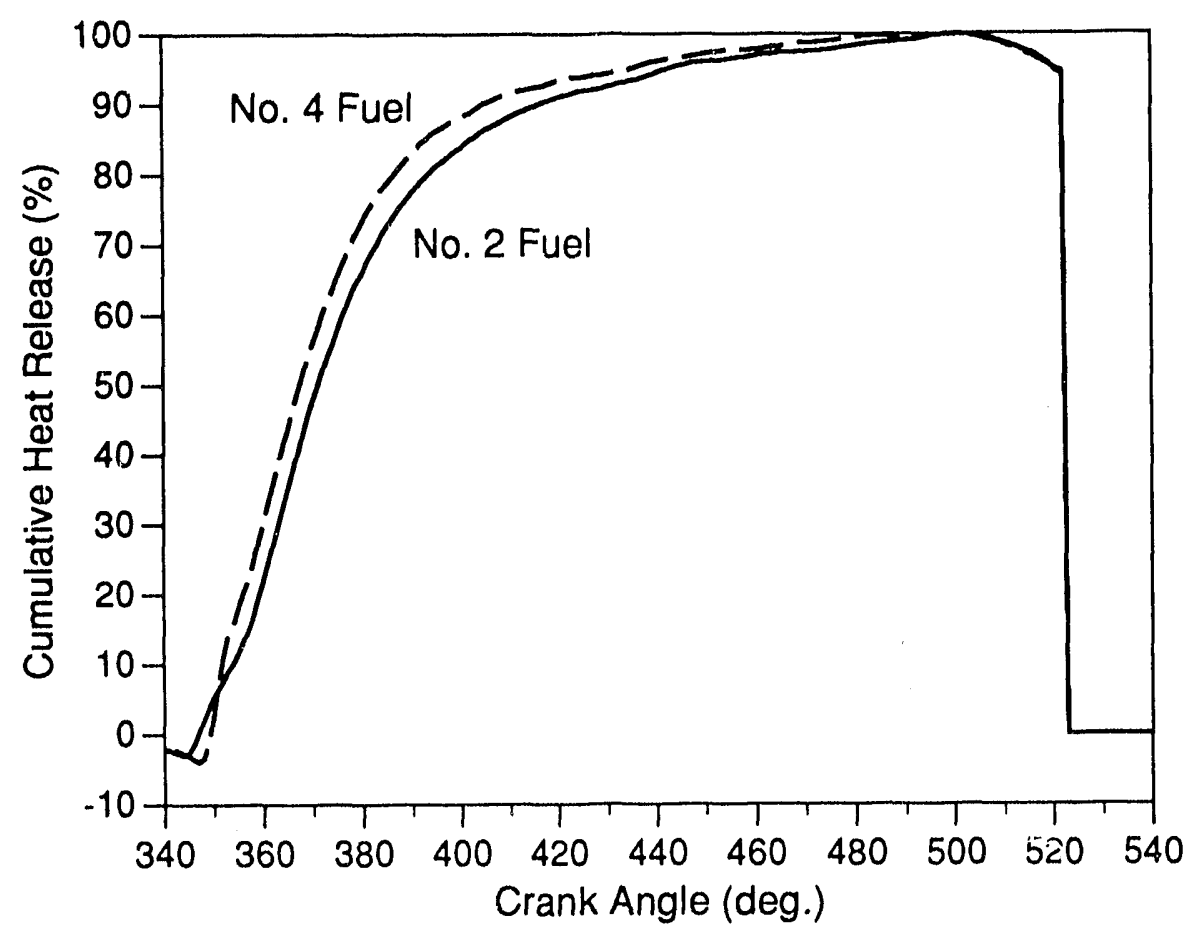

FIGURE 27 Cumulative Heat-Release Rates with No. 2 and No. 4 Diesel Fuels $\left(100 \%\right.$ load, $37.3 \mathrm{~kW}, 21 \% \mathrm{O}_{2}$, no water)

\subsubsection{Combustion Temperatures}

As part of the heat-release analysis, combustion gas temperatures are calculated as a function of crank angle. The gas temperature is a critical rate-controlling factor in the formation of $\mathrm{NO}_{\mathrm{X}}$. The comparisons presented here are meant to provide relative effects of oxygen and water levels on the combustion temperatures, which, in turn, would provide information about the effects on $\mathrm{NO}_{\mathrm{x}}$ formation. Figures 28 and 29 show comparisons of the effects of intake oxygen level and water content in the fuel on calculated gas temperatures. Because heat transfers to and from the cylinder walls are not included in the calculation, these temperatures should not be taken as the absolute values. When the oxygen level is increased to $35 \%$, the peak gas temperature increases by about $27 \%$. In addition, the rate of temperature rise is significantly higher, which explains the increase in $\mathrm{NO}_{\mathrm{x}}$ emissions. Introducing water into the combustion process (in the form of emulsified fuel) reduces the gas iemperature and the rate of temperature rise, which leads to lower $\mathrm{NO}_{\mathrm{x}}$ emissions.

Volume 2, App. A, contains a complete tabulation of all the measured and computed data from this series of tests. First, the data are listed in numerical sequence of test runs, and there are two pages of parameters for each run. Second, all the emissions are summarized for $50 \%$ and $100 \%$ loads with No. 2 diesel fuel and $50 \%$ and $100 \%$ loads for No. 4 fuel, respectively. The second tabulations also contain data obtained from the cylinder pressure diagrams on peak cylinder pressure and ignition delay. The tabulations are followed by a complete set of graphs prepared from the first series of data. 


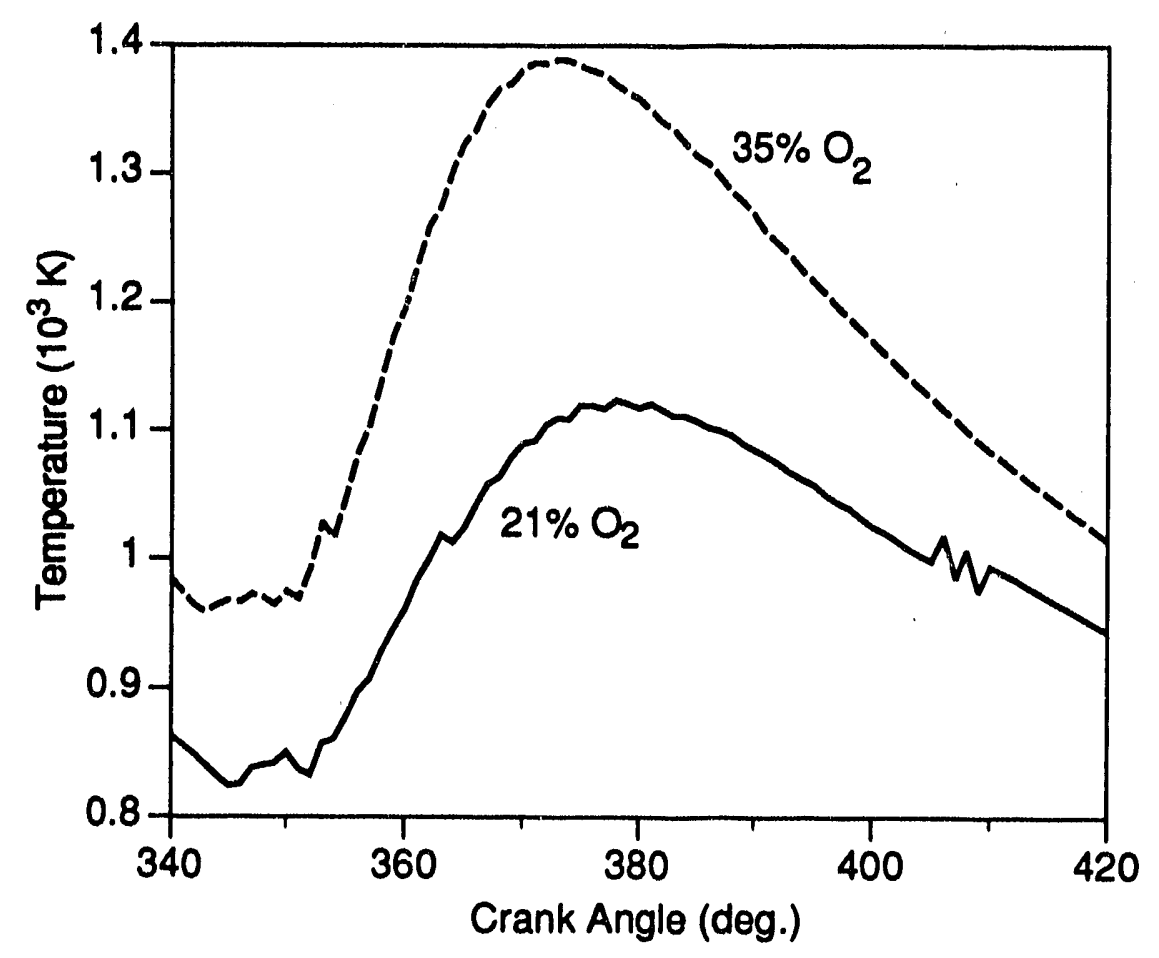

FIGURE 28 Effect of Oxygen Level on Calculated Gas Temperatures (No. 2 fuel, 100\% load, $37.3 \mathrm{~kW}$, no water)

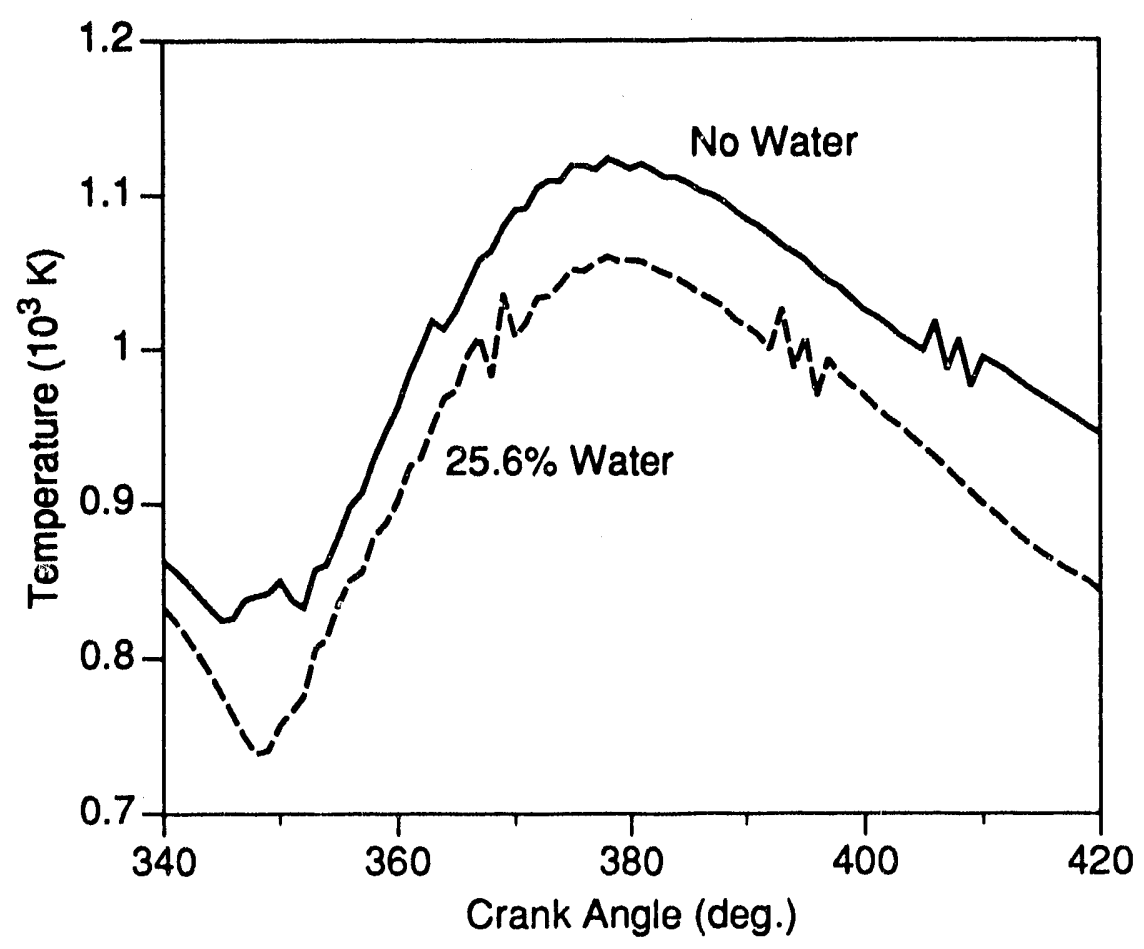

k.). GURE 29 Effect of Water in the Fuel on Calculated Gas Temperatures (No. 2 fuel, $100 \%$ load, $37.3 \mathrm{~kW}, 21 \% \mathrm{O}_{2}$ ) 


\subsection{Test Series II: Tests with an Oxygen-Enrichment Membrane}

The second series of single-cylinder engine tests was conducted using air enriched by an oxygen-selective membrane. (This study is the first to operate an engine with enriched air from a membrane.) Initially, the membrane performance was mapped without the engine. The membrane produced a 35\%-oxygen stream, but the flow rate was not adequate for the engine because the membrane was originally designed and used for another purpose. Shop air was mixed with the enriched air to obtain an adequate flow rate and to dilute the oxygen level to $27 \%$. Thus, the data obtained in this test series were limited to $27 \%$ oxygen. The major new parameter that was varied during this series was fuel injection timing. The base timing was $33 \mathrm{deg}$. before top dead center (btdc). Data were obtail:ed for two retarded timings: $27 \mathrm{deg}$. btdc and $22 \mathrm{deg}$. btdc. The same parameters as in the previous series were recorded. Only the constant-power cases were run, because the effects of increasing the power outpult in order to utilize the oxygen have been demonstrated in the earlier tests. Pure No. 2 and No. 4 fuels and 5\% water emulsions of these fuels were used.

Because the injection timing affects almost all aspects of diesel engine performance and emissions, the graphs are plotted as a function of injection timing. Figure 30 shows that the thermal efficiency decreases as the injection timing is retarded from $33 \mathrm{deg}$. btdc to $22 \mathrm{deg}$. btdc. However, the decrease is less pronounced at the higher oxygen level. The same trend in $\mathrm{NO}_{\mathbf{x}}$ emissions was noted (as shown in Fig. 31). In all diesel engines, there is a trade-off between $\mathrm{NO}_{\mathbf{x}}$ emissions and brake-specific fuel consumption (bsfc). When oxygen-enrichment technology is used, injection timing could be retarded to reduce $\mathrm{NO}_{\mathrm{x}}$ with less of a bsfc penalty than is the case for standard air. This comparison is shown in Fig. 32. Because ignition delay is decreased in an oxygen-enriched engine, this favorable trade-off is possible.

Similarly, $\mathrm{NO}_{\mathrm{x}}$ and particulate-matter emissions are also controlled in a trade-off mode. When injection timing is retarded to decrease $\mathrm{NO}_{\mathrm{x}}$ emissions, particulate-matter emissions increase. As can be seen from Fig. 33, the effect of retarding the timing on particulate-matter emissions is insignificant when oxygen-enriched air is used, compared standard air. The results regarding the use of pure No. 4 diesel fuel and fuel-water emulsions confirmed the earlier trends.

Volume 2, App. B, contains the tabulated data of tests in the second series. The tabulations are followed by graphs plotted from the data.

\subsection{Problems Encountered during Experiments}

No major engine problem was encountered during both series of tests. However, because water-emulsified fuels were used, injector calihrations seemed to go out of order, and the injector had to be replaced about six times. The 112 runs in the first series were completed during $285 \mathrm{~h}$ of engine operation. Near the end of the series, the smoke level increased, which indicated a problem with the piston ring. Upon disassembly of the engine, we discovered scuffing of the piston and the liner. Because oxygen-enriched combustion results in high temperatures, the piston apparently expanded more than what one would consider to be normal. This abnormal expansion indicates 


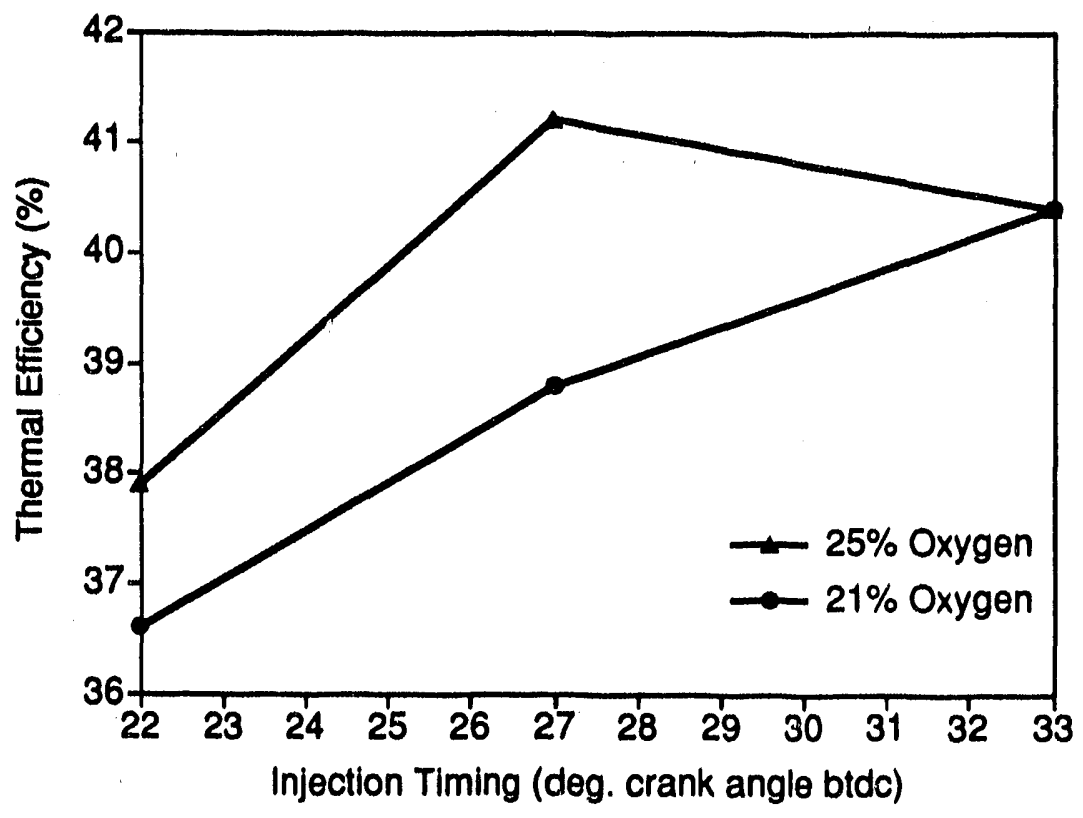

FIGURE 30 Effect of Injection Timing on Thermal Efficiency

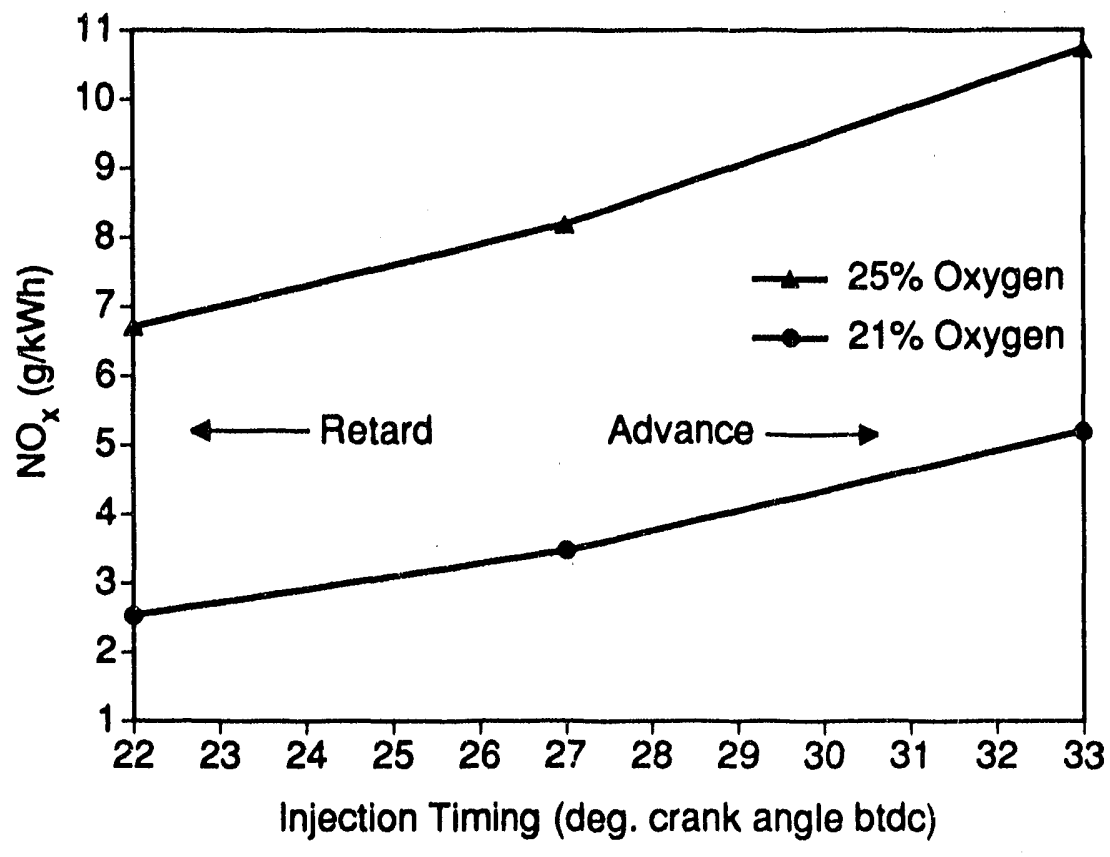

FIGURE 31 Effect of Injection Timing on $\mathrm{NO}_{\mathrm{x}}$ Emissions 


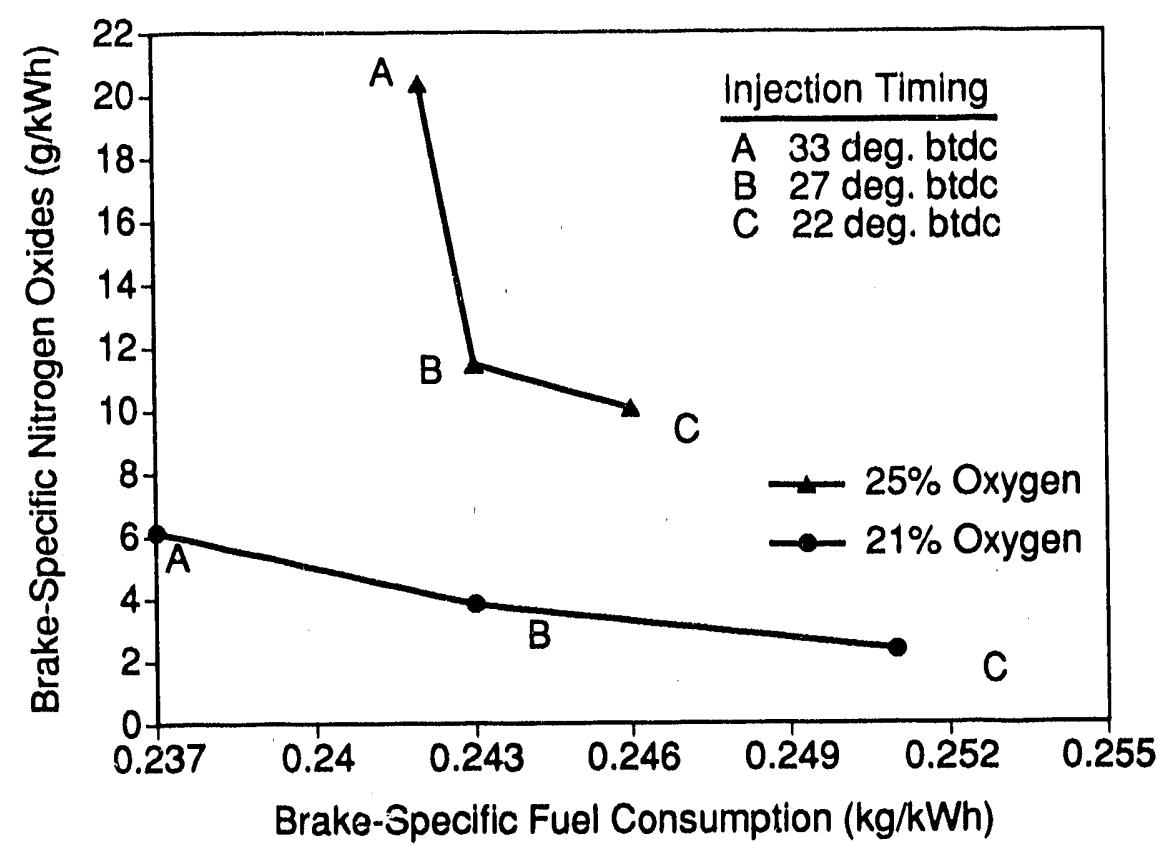

FIGURE 32 Trade-Off between Brake-Specific $\mathrm{NO}_{x}$ and Brake-Specific Fuel Consumption

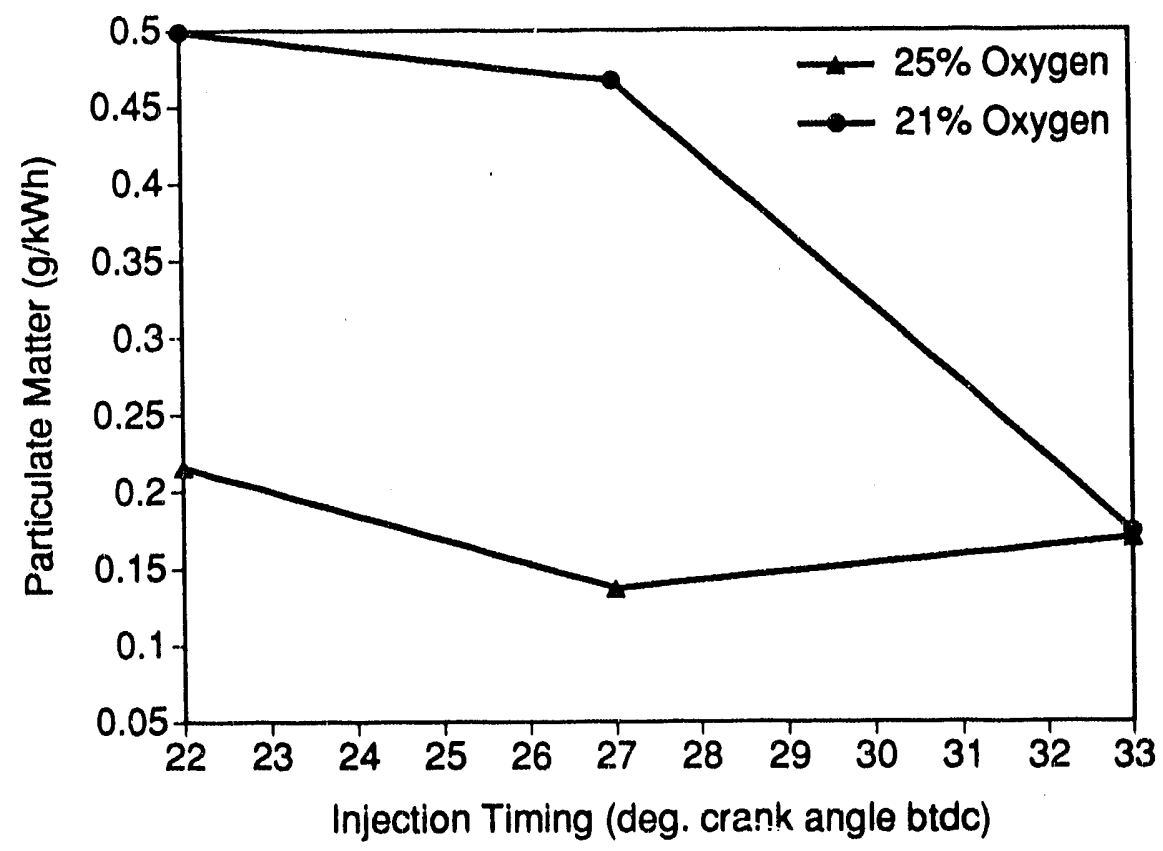

FIGURE 33 Effect of Injection Timing on Particulate Matter 
that a minor redesign of the piston skirt to increase running clearances may be necessary. Finiteelement analysis of the piston profile could be employed to solve this problem.

The method of preparing fuel-water emulsions resulted in inconsistent composition, particularly for No. 2 fuel emulsions. A known weight of distilled water was added to a known weight of base fuel (No. 2 or No. 4 diesel) in a 55-gal drum, and the mixture was constantly stirred by means of a homogenizer pump. The No. 2 fuel tended to separate quickly from the water. The use of different types and quantities of emulsifying agents partially alleviated the problem. Wide variations were noticed in the overall water content of the test fuel and the water content during a data run. Therefore, fuel samples were therefore taken immediately before and after the recording of data. The water contents were analyzed in the chemistry laboratory, and the average of the two values was used for analysis of the data. In the future, it is recommended that a commercially available emulsifier be used to prepare the emulsion "on demand" by the engine.

\subsection{Emission Repeatability Tests}

Two special test sequences were carried out at the conclusion of the second series of the test program to examine the repeatability of emission measurements. The tests were run at two retarded fuel injection timings. The first test was run on October 25, 1990, with the injection timing set at $22 \mathrm{deg}$. btdc and the engine operated at the $100 \%$-load condition $(50 \mathrm{hp})$. Ten data points were collected at approximately 30 -min intervals on the same day. The second test sequence was run on the following day, with the injection timing set at $27 \mathrm{deg}$. btdc and the engine operated at the 50\%-load condition ( $25 \mathrm{bhp}$ ). Nine data points were collected in the manner described for the first test sequence. The standard No. 2 diesel fuel and $21 \%$-oxygen intake air were used in both cases. The test results of the first and second sequences are shown in Tables 3 and 4 , respectively. Also shown are data from calibration runs that were conducted on various dates immediately preceding tests in the second series. Graphs of the measured data are shown in Figs. 34-39 for the two cases.*

Statistical analyses were performed on the data. The results are shown on the top portion of the respective tables. In addition to the emissions data (i.e., particulate matter, $\mathrm{NO}_{\mathrm{x}}$, and smoke), measurements of the gas temperature and the oxygen content of the exhaust are presented in the tables. For each parameter, the average value and standard deviation were calculated. Calculated values for data taken on a single day are listed under same-day measurements, while for the data taken on different days, including those of the same-day measurements, are listed under different-day measurements. Both tables show that data taken on a single day have standard deviations much smaller than those taken on different days. This difference seems to indicate that running the tests on different days might bias the results and that, in the planning of the next series of tests, it might be desirable to group certain tests together to be run on a single day to avoid the bias.

\footnotetext{
*Statistical analyses were done in British units. Data were plotted in metric units.
} 
TABLE 3 Emissions Repeatability Tests: First Test Sequence (50 bhp, No. 2 fuel, $0 \%$ water, 22 deg. btdc injection timing)

\begin{tabular}{|c|c|c|c|c|c|c|c|c|}
\hline & & & \multicolumn{3}{|c|}{ Same-Day Measurements } & \multicolumn{3}{|c|}{ Different-Day Measurements } \\
\hline \multicolumn{3}{|c|}{ Parameter } & Average & \multicolumn{2}{|c|}{ Standard Deviation } & \multirow{2}{*}{$\begin{array}{r}\text { Average } \\
0.27 \\
1.39 \\
56.28 \\
832.22 \\
11.80\end{array}$} & \multicolumn{2}{|c|}{ Standard Deviation } \\
\hline $\begin{array}{l}\text { Particulate } \\
\mathrm{NO}_{\mathrm{x}}(\mathrm{g} / \mathrm{hph} \\
\mathrm{Smoke}(\%) \\
\text { Exhaust ter } \\
\mathrm{O}_{2} \text { exhaust }\end{array}$ & $\begin{array}{l}\text { natter ( } 9 \\
\text { perature } \\
\% \text { ) }\end{array}$ & $\begin{array}{l}\text { hph) } \\
\left({ }^{\circ} \mathrm{F}\right)\end{array}$ & $\begin{array}{r}0.26 \\
1.15 \\
64.30 \\
822.60 \\
12.00\end{array}$ & $\begin{array}{r}0.03538 \\
0.05 \\
3.56 \\
2.72 \\
0.06\end{array}$ & $\begin{array}{l}(13.5 \%) \\
(4.4 \%) \\
(5.5 \%) \\
(0.5 \%)\end{array}$ & & $\begin{array}{r}0.04390 \\
0.38 \\
12.26 \\
22.27 \\
0.37\end{array}$ & $\begin{array}{l}(16.2 \%) \\
(27.3 \%) \\
(21.8 \%) \\
(0.3 \%)\end{array}$ \\
\hline Date & Time & $\mathrm{O}_{2} \mathrm{~F}$ & $\begin{array}{l}\text { haust } \\
\text { o) }\end{array}$ & $\begin{array}{c}\text { Exhaust } \\
\text { Temperature } \\
\text { ( } \mathrm{\circ} \text { ) }\end{array}$ & $\begin{array}{c}\text { Simoke } \\
(\%)\end{array}$ & $\begin{array}{l}\text { Particulate } \\
\text { Matter } \\
\text { (g/hph) }\end{array}$ & $\begin{array}{c}\mathrm{NO}_{\mathrm{x}} \\
(\mathrm{g} / \mathrm{hph})\end{array}$ & Run \# \\
\hline $\begin{array}{l}10 / 25 / 90 \\
10 / 25 / 90 \\
10 / 25 / 90 \\
10 / 25 / 90 \\
10 / 25 / 90 \\
10 / 25 / 90 \\
10 / 25 / 90 \\
10 / 25 / 90 \\
10 / 25 / 90 \\
10 / 25 / 90 \\
10 / 23 / 90 \\
10 / 11 / 90 \\
10 / 11 / 90 \\
09 / 06 / 90 \\
07 / 16 / 90 \\
09 / 26 / 90 \\
09 / 06 / 90 \\
07 / 16 / 90\end{array}$ & $\begin{array}{l}1010 \\
1040 \\
1110 \\
1140 \\
1240 \\
1310 \\
1340 \\
1425 \\
1455 \\
1525 \\
1123 \\
1020 \\
1513 \\
1315 \\
1425 \\
1457 \\
1245 \\
1340\end{array}$ & $\begin{array}{l}12 \\
11 \\
12 \\
12 \\
12 \\
12 \\
12 \\
12 \\
11 \\
12 \\
12 \\
11 \\
11 \\
11 \\
11 \\
11 \\
11 \\
10\end{array}$ & & $\begin{array}{l}818 \\
821 \\
819 \\
826 \\
824 \\
825 \\
825 \\
823 \\
824 \\
821 \\
825 \\
801 \\
803 \\
867 \\
867 \\
853 \\
868 \\
870\end{array}$ & $\begin{array}{l}60 \\
58 \\
62 \\
64 \\
63 \\
65 \\
67 \\
68 \\
68 \\
68 \\
64 \\
55 \\
32 \\
52 \\
35 \\
36 \\
56 \\
40\end{array}$ & $\begin{array}{l}0.33 \\
0.30 \\
0.25 \\
0.25 \\
0.30 \\
0.22 \\
0.22 \\
0.26 \\
0.24 \\
0.24 \\
0.24 \\
0.24 \\
0.28 \\
0.37 \\
0.32 \\
. \\
- \\
.\end{array}$ & $\begin{array}{l}1.12 \\
1.13 \\
1.11 \\
1.11 \\
1.09 \\
1.22 \\
1.22 \\
1.18 \\
1.18 \\
1.15 \\
1.35 \\
1.83 \\
2.31 \\
1.89 \\
1.16 \\
1.93 \\
1.86 \\
1.18\end{array}$ & $\begin{array}{l}241 \\
213 \\
205\end{array}$ \\
\hline
\end{tabular}


TABLE 4 Emissions Repeatability Tests: Second Test Sequence (25 bhp, No. 2 fuel, n\% water, 27 deg btdc injection timing)

\begin{tabular}{|c|c|c|c|c|c|c|}
\hline \multirow[b]{2}{*}{ Parameter } & \multicolumn{3}{|c|}{ Same-Day Measurements } & \multicolumn{3}{|c|}{ Different-Day Measurements } \\
\hline & Average & Standard & Deviation & Average & Standard & Jeviation \\
\hline $\begin{array}{l}\text { Particulate matter (g/hph) } \\
\mathrm{NO}_{x}(\mathrm{~g} / \mathrm{hph}) \\
\text { Smoke }(\%) \\
\text { Exhaust temperature }\left({ }^{\circ} \mathrm{F}\right) \\
\mathrm{O}_{2} \text { exhaust }(\%)\end{array}$ & $\begin{array}{r}0.28 \\
1.16 \\
56.78 \\
559.78 \\
14.46\end{array}$ & $\begin{array}{r}0.03004 \\
0.16 \\
1.48 \\
4.41 \\
0.12\end{array}$ & $\begin{array}{l}(10.6 \%) \\
(13.8 \%) \\
(2.6 \%) \\
(0.8 \%)\end{array}$ & $\begin{array}{r}0.32 \\
1.76 \\
54.40 \\
567.47 \\
14.33\end{array}$ & $\begin{array}{r}0.093929 \\
0.79 \\
8.77 \\
12.09 \\
0.22\end{array}$ & $\begin{array}{l}(29.5 \%) \\
(44.9 \%) \\
(16.1 \%) \\
(1.5 \%)\end{array}$ \\
\hline
\end{tabular}

\begin{tabular}{lccccccc}
\hline Date & Time & $\begin{array}{c}\text { O Exhaust } \\
(\%)\end{array}$ & $\begin{array}{c}\text { Exhaust } \\
\text { Temperature } \\
(\%)\end{array}$ & $\begin{array}{c}\text { Smoke } \\
(\%)\end{array}$ & $\begin{array}{c}\text { Particulate } \\
\text { Matter } \\
(\mathbf{g} / \mathrm{hph})\end{array}$ & $\begin{array}{c}\text { NO } \\
(\mathrm{g} / \mathrm{hph})\end{array}$ & Run \# \\
\hline $10 / 26 / 90$ & 1040 & 14.60 & 557 & 54 & 0.26 & 1.36 & \\
$10 / 26 / 90$ & 1110 & 14.60 & 555 & 57 & 0.26 & 1.34 & \\
$10 / 26 / 90$ & 1140 & 14.60 & 556 & 55 & 0.23 & 1.33 & \\
$10 / 26 / 90$ & 1240 & 14.40 & 559 & 57 & 0.29 & 1.20 & \\
$10 / 26 / 90$ & 1310 & 14.50 & 556 & 56 & 0.31 & 1.16 & \\
$10 / 26 / 90$ & 1340 & 14.40 & 559 & 58 & 0.33 & 1.04 & \\
$10 / 26 / 90$ & 1440 & 14.40 & 564 & 58 & 0.30 & 1.04 & 1.00 \\
$10 / 26 / 90$ & 1500 & 14.30 & 566 & 58 & 0.31 & 0.96 & \\
$10 / 26 / 90$ & 1525 & 14.30 & 566 & 58 & 0.27 & 2.33 & \\
$10 / 22 / 90$ & 1138 & 14.32 & 563 & 63 & 0.18 & 2.59 & \\
$10 / 05 / 90$ & 1148 & 14.10 & 585 & 60 & 0.44 & 2.97 & 234 \\
$10 / 05 / 90$ & 1317 & 13.91 & 586 & 45 & 0.49 & 2.84 & 211 \\
$09 / 05 / 90$ & 1655 & 14.00 & 586 & 54 & 0.48 & 2.29 & \\
$10 / 03 / 90$ & 1252 & 14.44 & 568 & 26 & - & 2.87 \\
$09 / 05 / 90$ & 1620 & 14.08 & 586 & 57 &. & \\
\hline
\end{tabular}




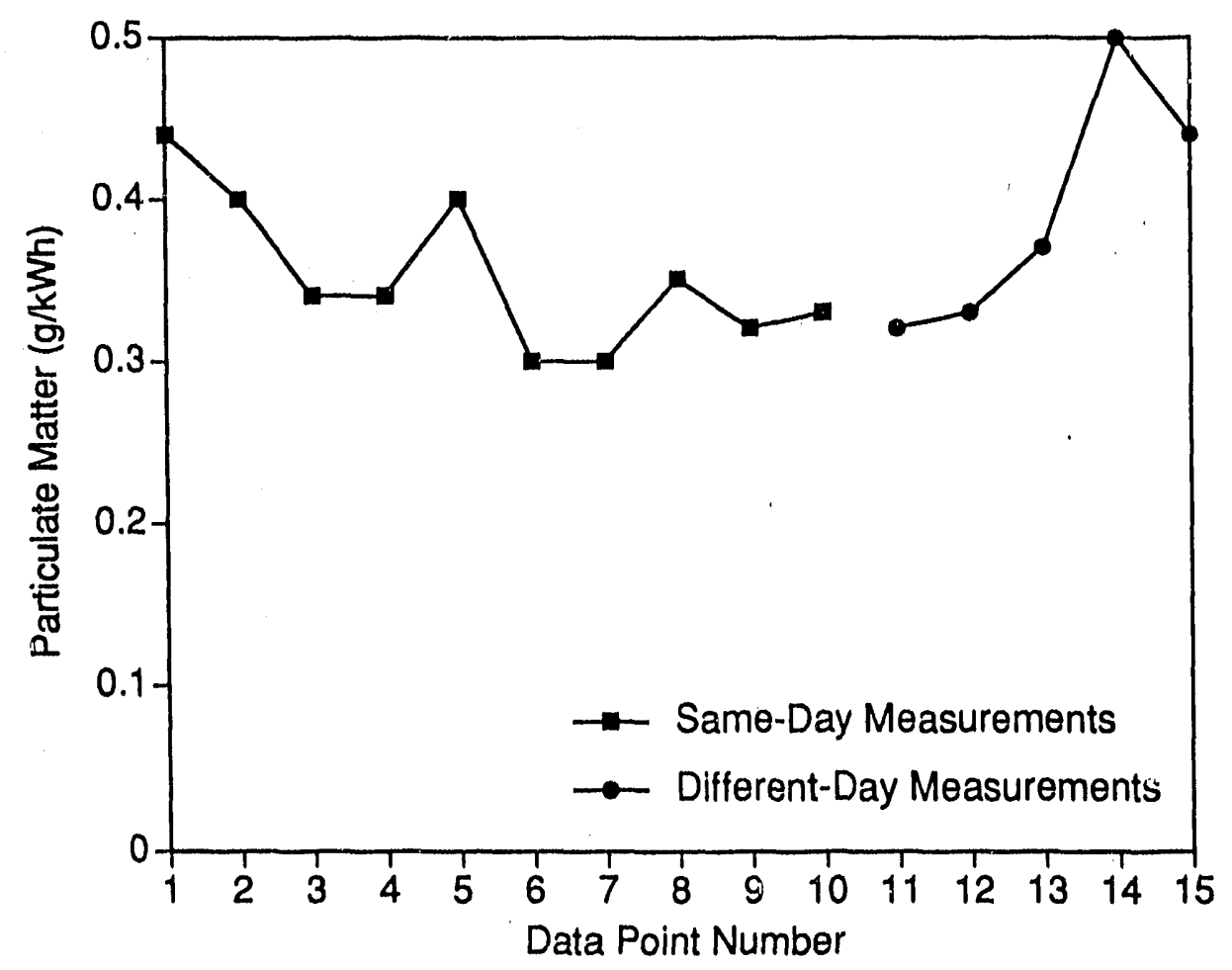

FIGURE 34 Emission Repeatability Tests, Particulate-Matter Measurements: 50 bhp

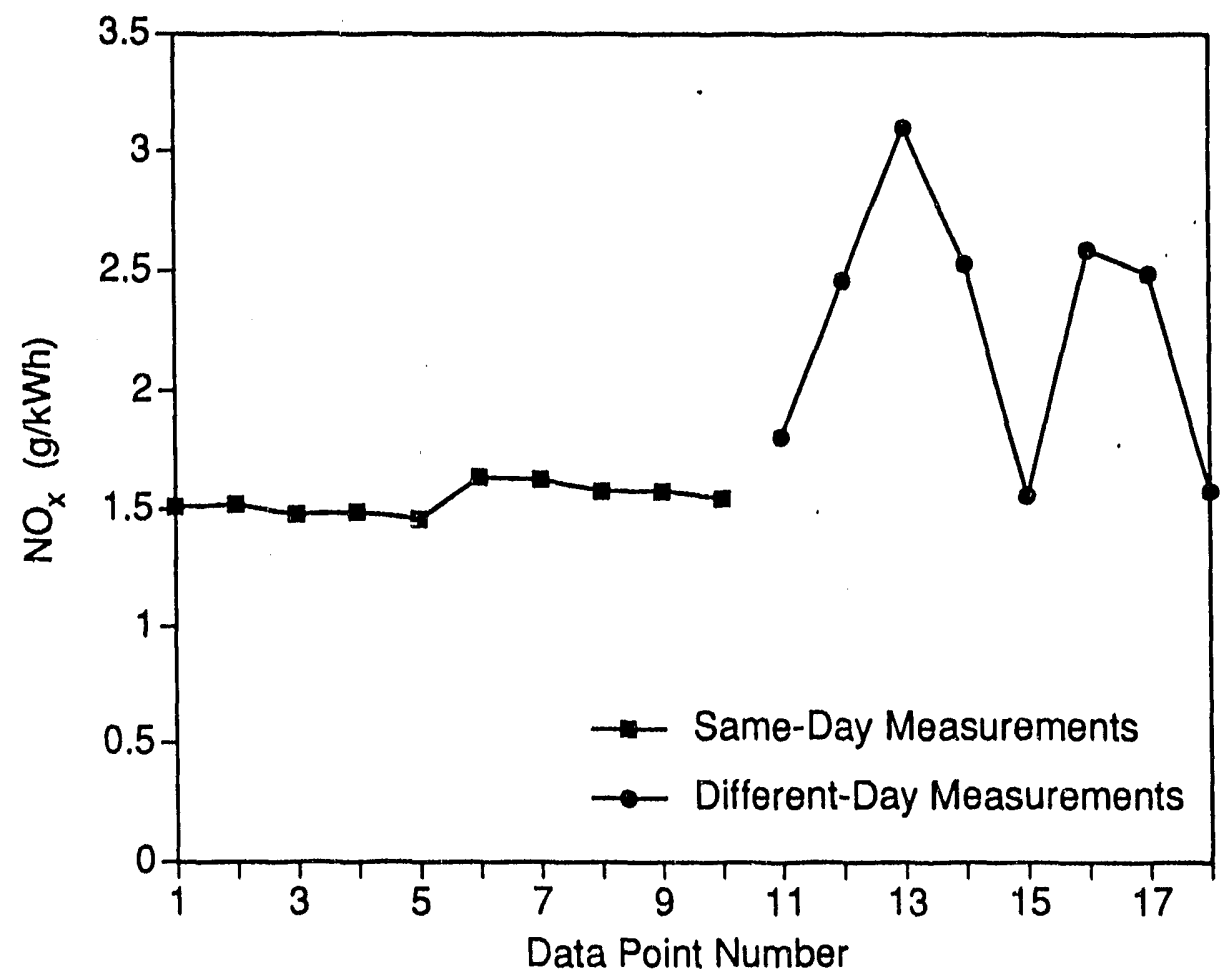

FIGURE 35 Emission Repeatability Tests, NO Measurements: 50 bhp 


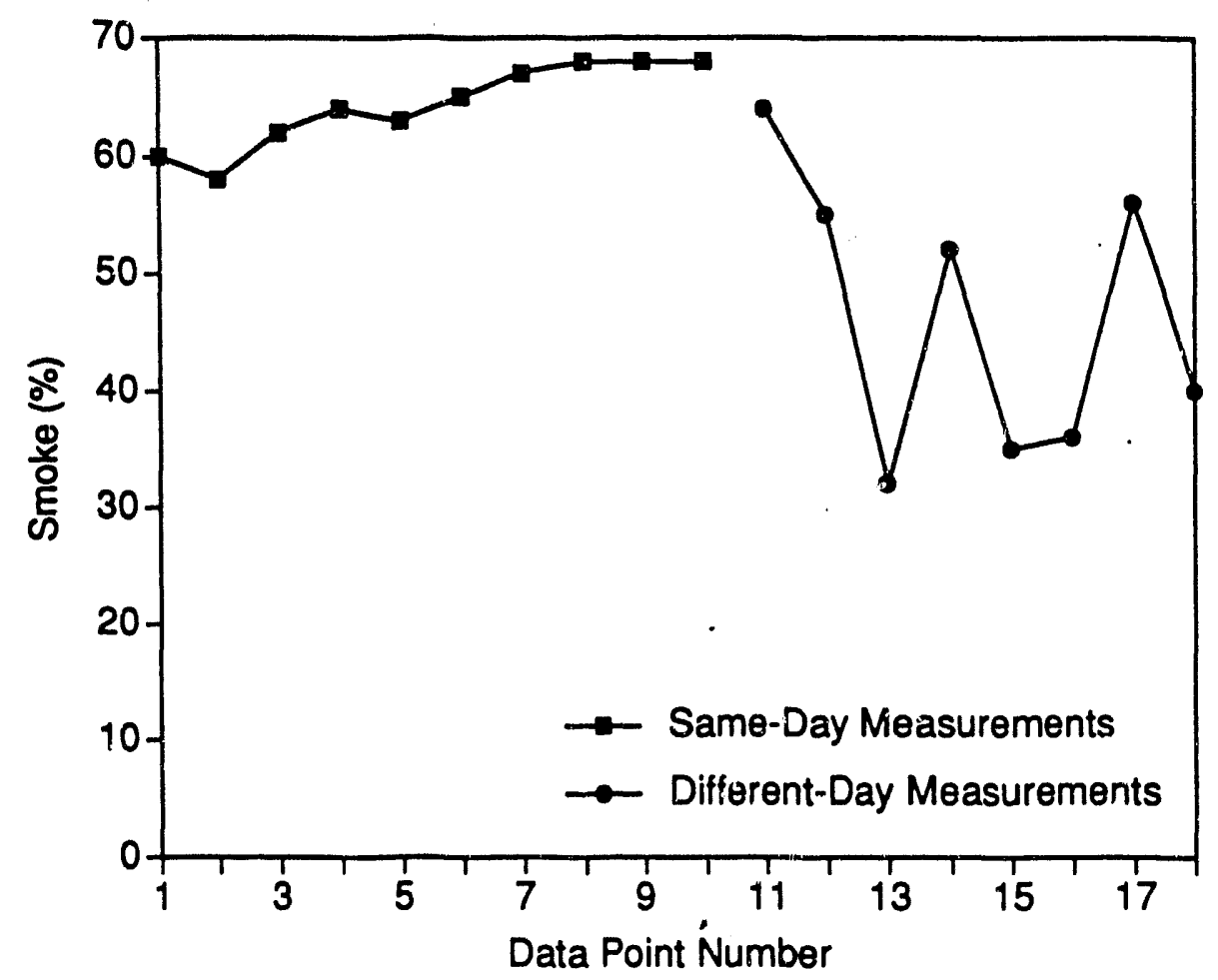

FIGURE 36 Emission Repeatability Tests, Smoke Measurements: 50 bhp

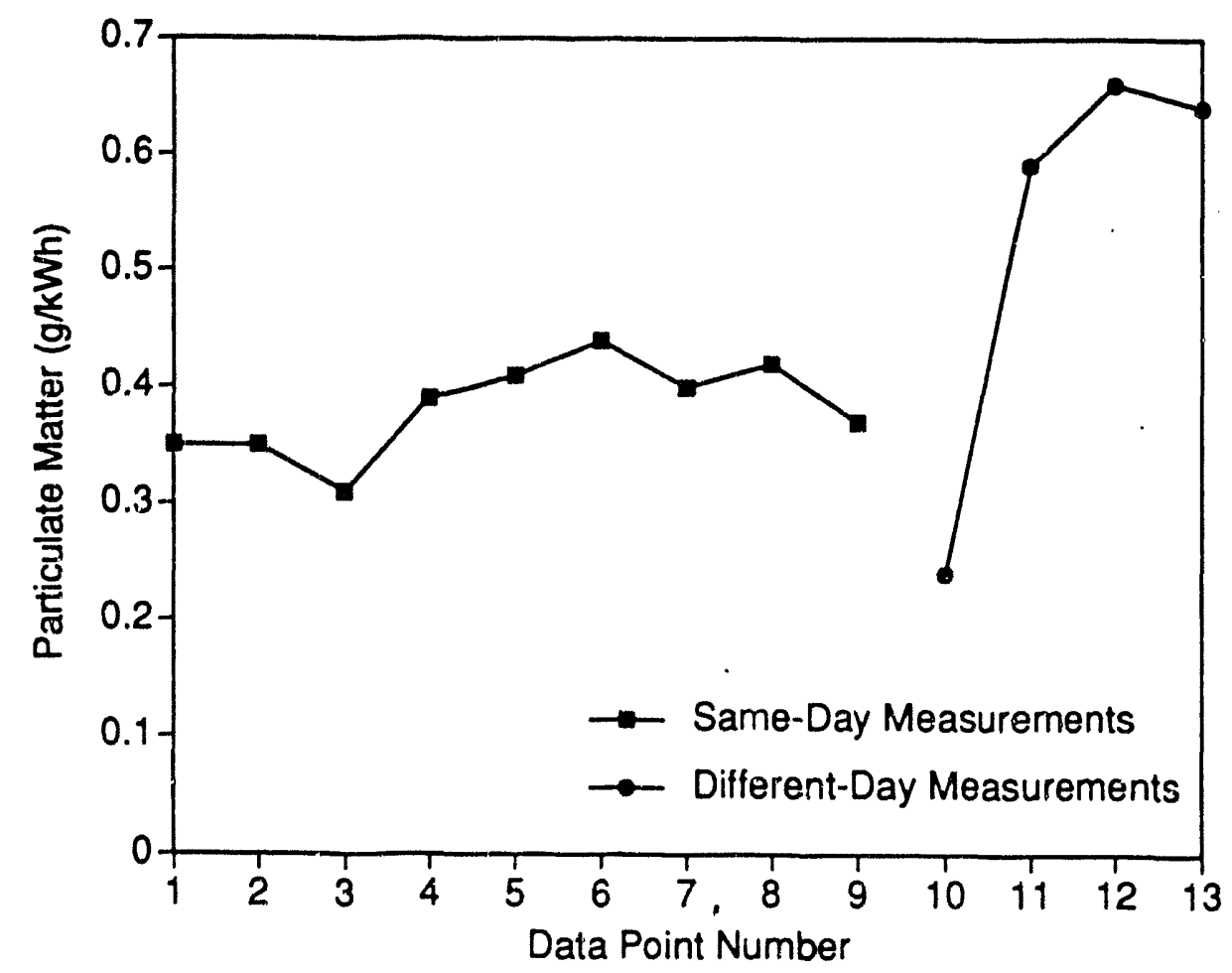

FIGURE $? 7$ Emission Repeatability Tests, Particulate-Matter Measurements: 25 bhp 


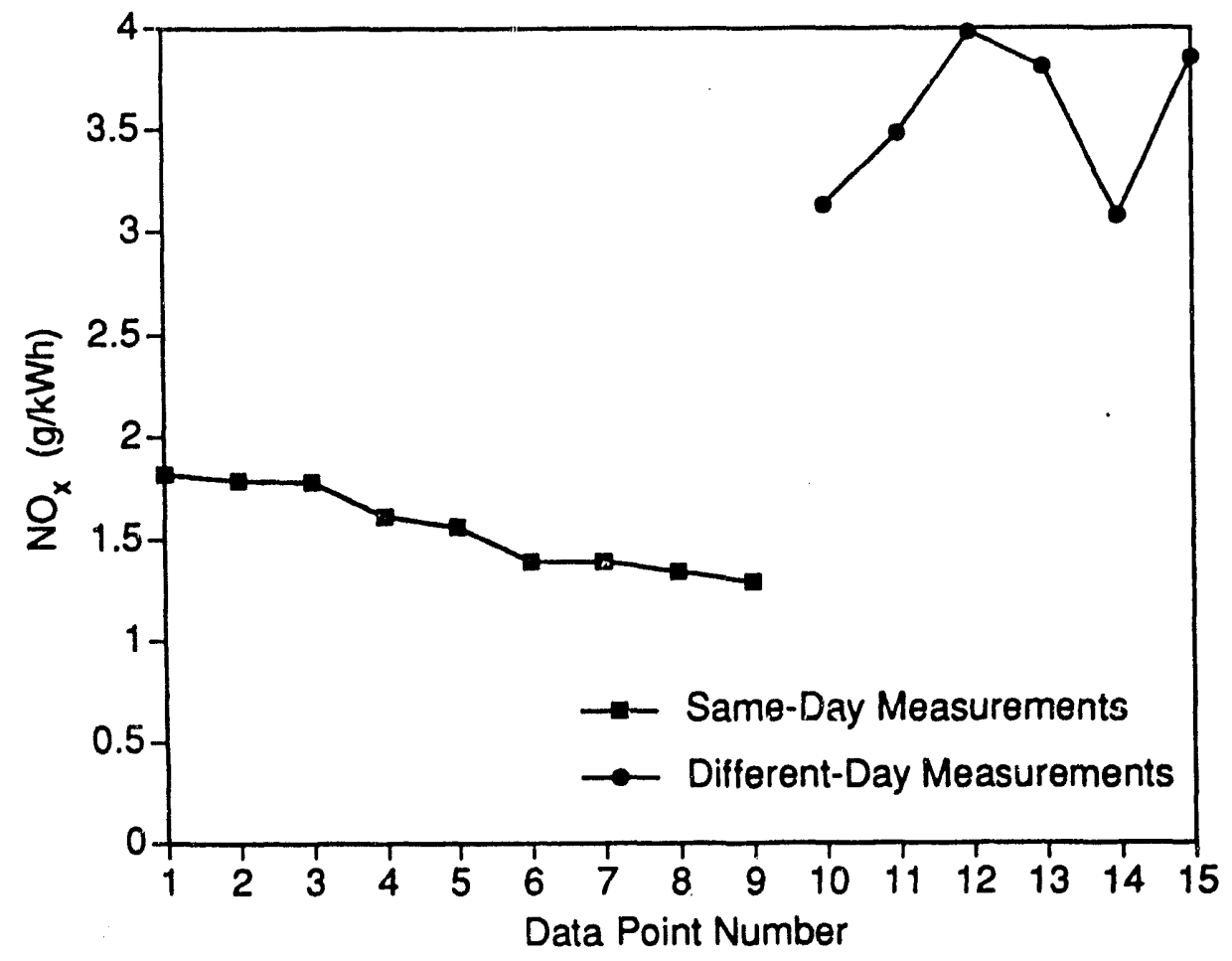

FIGURE 38 Emission Repeatability Tests, NO Measurements: 25 bhp

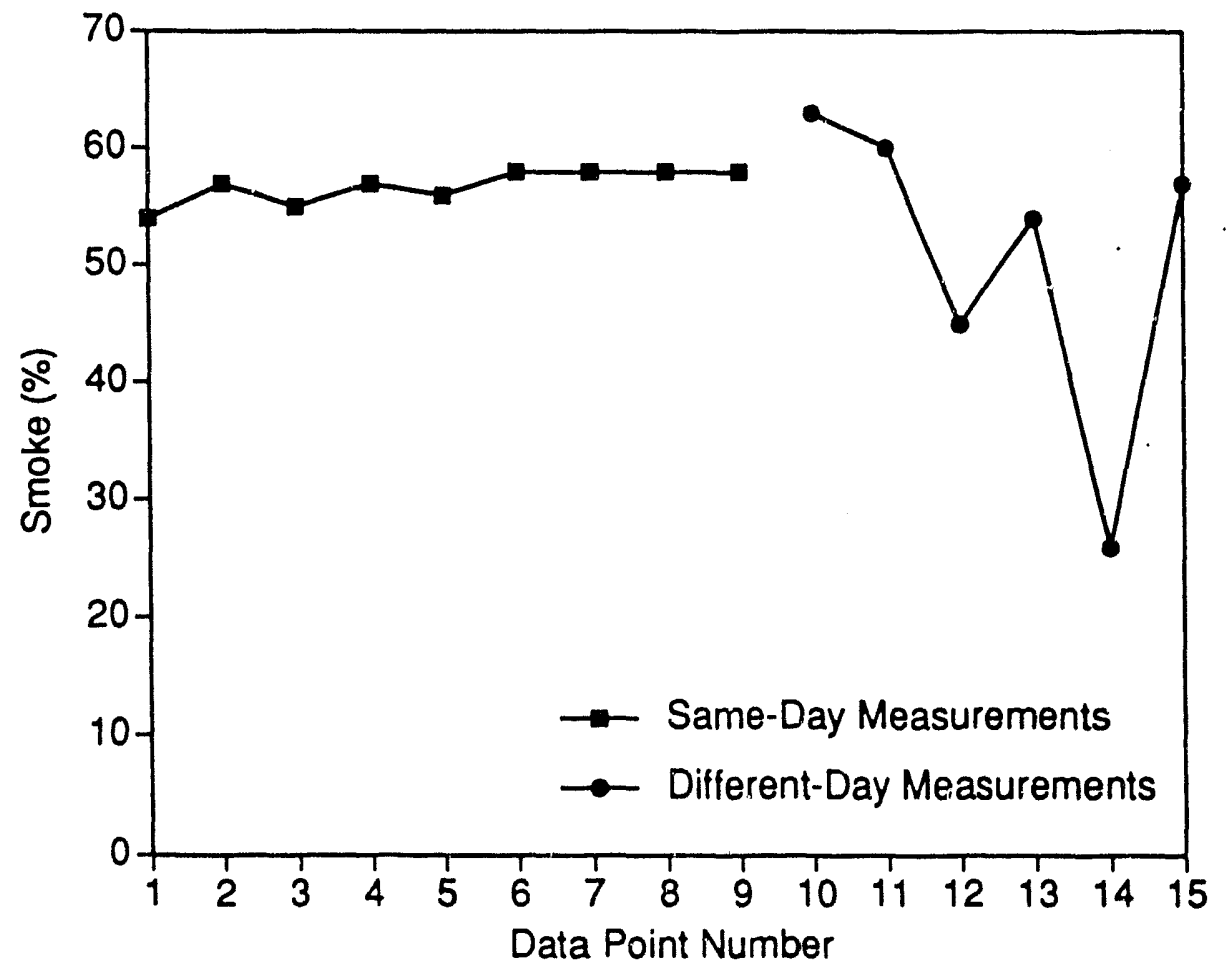

FIGURE 39 Emission Repeatability Tests, Smoke Measurements: 25 bhp 


\section{Conclusions and Recommendations}

On the basis of the results of the experimental program discussed in the previous sections, the following conclusions regarding the performance of a diesel engine using oxygen-enriched combustion air and emulsified diesel fuels are drawn:

1. Oxygen enrichment of combustion air and the use of emulsified light- and heavy-liquid fuels are viable technologies through which the performance of diesel engines can be improved.

2. When oxygen-enriched combustion air is employed, fuel input and power output of the engine can be increased to use the excess oxygen. The additional power is limited primarily by the exhaust temperature.

3. The demonstrated potential for a $40-60 \%$ increase in the power density of the diesel engine is important in industrial cogeneration and ciher power generation plants because such an increase could significantly reduce capital costs.

4. Fuel emulsification and oxygen enrichment will make it more likely that lessexpensive liquid fuels (such as No. 4 and No. 6 fuel oils) could be used in medium- and high-speed diesel engines.

5. Water emulsification of the fuel in moderate amounts (about $5 \%$ by weight), along with oxygen enrichment, can improve thermal efficiency. Conversely, with higher amounts of water, engine thermal efficiency is not significantly decreased.

6. Oxygen enrichment reduces or eliminates visible smoke, and even a slight increase in the oxygen level increases the power limit imposed by smoke emissions.

7. Oxygen enrichment at $30 \%$ decreases ignition delay by about 5 deg. crank angle at $1800 \mathrm{rpm}$. This reduction allows for the retardation of injection timing, reduces $\mathrm{NO}_{\mathrm{x}}$ ernissions, and results in only a minor penalty in fuel consumption. Heavier fuel (No. 4) has a longer ignition delay than does No. 2 diesel fuel.

8. Oxygen enrichment, by itself, increases the level of $\mathrm{NO}_{\mathrm{x}}$ emissions from the engine. However, when the power output is increased in order to use the excess oxygen, the brake-specific $\mathrm{NO}_{x}$ emissions remain near base levels. Retarding the injection timing and introducing water into the combustion process can significantly decrease $\mathrm{NO}_{\mathrm{x}}$ emissions.

9. The data on particulate-matter emissions were not conclusive. Because the engine already had a low level of particulate-matter emissions, scatter in the 
measurements tended to obscure any quantitative trends. However, on the basis of reduced smoke emissions, particulate-matter emissions may decrease with increasing oxygen levels.

10. Oxygen enrichment and the resulting higher power output increases cylinder pressures. At an intake boost level corresponding to $50 \%$ rated power, peak pressure is increased by about $15 \%$ when the power is increased by $140 \%$. Thus, engine redesign may not be required. On the other hand, the use of a turbocharger to achieve the same increase in power would increase cylinder pressures to prohibitively high levels.

11. Oxygen enrichment causes a higher proportion of the fuel energy to be released in the early part of the combustion process. This phenomenon should be considered when combustion chamber geometry and process parameters are optimized.

12. Because it was demonstrated that a membrane separator could be used to enrich the oxygen as part of a diesel engine system, the further application of the concept is at least technically feasible. Although current oxygen-enrichment systems operate at inlet pressures of 100 psig and thus represent a considerable parasitic loss, the increased engine power will exceed these losses. It is not likely that the engine will need major modification in order to incorporate the membrane system.

13. No attempt was made in these experiments to optimize the operating variables. However, combining the two technologies should allow an engine designer two more degrees of freedom to improve the performance of the cogeneration system and reduce emissions.

In light of the foregoing conclusions, the following recommendations are made:

1. A low-pressure-drop, low-cost membrane designed specifically for oxygen production should be developed because it is the most critical technical and economic problem to address. The size of the membrane should also be reduced, although this is not a serious problem in industrial cogeneration applications.

2. Multicylinder engine tests, in which bottled oxygen is used, should be conducted in order to investigate the scale-up potential of the single-cylinder data. Such multicylinder engine tests also would highlight any problems that may be connected with operating a turbocharger with oxygen-enriched combustion air.

3. Engine design and operating variables should be investigated in order to optimize the most acceptable trade-offs between the emissions parameters $\left(\mathrm{NO}_{x}\right.$ and particulate matter) and thermal efficiency. 
4. A review of current and proposed industrial cogeneration installations indicate that systems based on diesel engines play a relatively small role in such installations, except in special situations in smaller industrial applications. The successful application of the concept discussed in this report would offer designers and operators significant flexibility. Therefore, it is recommended that application-specific studies be done to highlight the benefits and probiems of using oxygen-enrichment and water-injection technologies.

5. At this stage of development, manufacturers should be involved in technology transfer and in the commercialization of these technologies. One way to accomplish these tasks is for DOE to let cost-shared contracts out to the manufacturers. The assembly of a team of engine and membrane manufacturers to develop and demonstrate a specific system would be a good first step. Another method would be to form a government-industry consortium, in which interested paries would pool their resources and resolve any remaining fundamental technical problems.

6. In the short run, the interest of engine manufacturers in these technologies lies in their potenuial for emissions reduction. So far only steady-state emissions data at one engine speed have been obtained. The data showed considerable scatter in particulate-matter emissions and $\mathrm{NO}_{x}$ measurements. It is important to accurately map the emissions aspects of these technologies in order to sustain the interests of engine manufacturers. Complete emissions data should be obtained in a series of multicylinder engine tests.

7. The transient response of membrane separators should be carefully evaluated. The most serious smoke problems of diesel engines occur during acceleration. Therefore, it is critical that the membrane respond at least as fast as the rest of the engine.

8. Attempts should be made to develop systems to recover or utilize the energy from the nitrogen-rich waste stream. 


\section{References}

1. Wartinbee, W.J., Jr., Emissions Study of Oxygen-Enriched Air, Society of Automotive Engineers Paper No. 710606, Detroit (1971).

2. Quader, A.A., Exhaust Emissions and Performance of a Spark-Ignition Engine Using Oxygen-Enriched Intake Air, Combustion Science and Technology, 19:81-86 (1978).

3. Ghojel, J., J.C. Hillard, and J.A. Levendis, Effect of Oxygen-Enrichment on the Performance and Emissions of I.D.I. Diesel Engines, Society of Automotive Engineers Paper No. 830245, Detroit (1983).

4. Iida, N., et al., Effects of Intake Oxygen Concentration on the Characteristics of Particulate Emissions from a D.I. Diesel Engine, Society of Automotive Engineers Paper No. 861233, Detroit (1986).

5. Iida, N., and G.T. Sato, Temperature and Mixing Effects on $N O_{x}$ and Particulates, Society of Automotive Engineers Paper No. 880424, Detroit (1988).

6. Watson, H.C., E.E. Milkins, and G.R. Rigby, A New Look at Oxygen Enrichment (1) The Diesel Engine, Society of Automotive Engineers Paper No. 900344, Detroit (1990).

7. Willumeit, H.-P., and M. Bauer, Emissions and Performance of an S.I. Engine Inducting Oxygen-Enriched Combustion Air (in German), MTZ Motortechnische Zeitschrift 49(4):149-152 (1988).

8. Whipple, J.G., and K.W. Ragland, Test and Evaluation of Polymeric Membranes for Oxygen Enrichment of Air, U.S. Department of Energy Report DOE/ID/12710-1 (July 1989).

9. Gollan, A.Z., and M.H. Kleper, Research into an Asymmetric Membrane Hollow Fiber Device for Oxygen-Enriched Air Production (Phase II Final Report), U.S. Department of Energy Report DOE/ID/12429-1 (1985).

10. Kobayashi, H., Oxygén-Enriched Combustion System Performance Study, U.S. Department of Energy Report DOE/ID/12597 (1987).

11. Valdmanis, E., and D.E. Wulfhorst, The Effects of Emulsified Fuels and Water Induction on Diesel Combustion, Society of Automotive Engineers Paper No. 700736, Detroit (1970).

12. Greeves, G., I.M. Khan, and G. Onion, Effects of Water Introduction on Diesel Engine Combustion and Emissions, 16th Symp. (International) on Combustion, The Combustion Institute, Pittsburgh, Penn., pp. 321-336 (Aug. 1976). 
13. Assanis, D.A., et al., Simulation Studies of Diesel Engine Performance with Oxygen Enriched Air and Water Emulsified Fuels, American Society of Mechanical Engineers Paper No. 90-ICE-17, Published at the Energy-Sources Technology Conf. and Exhibition, New Orleans, La. (Jan. 1990).

14. Cole, R.L., et al., Technical and Economic Evaluation of Diesel Engine with Oxygen Enrichment and Water Injection, American Society of Mechanical Engineers Paper No. 90-ICE-1 (Jan. 1990). 

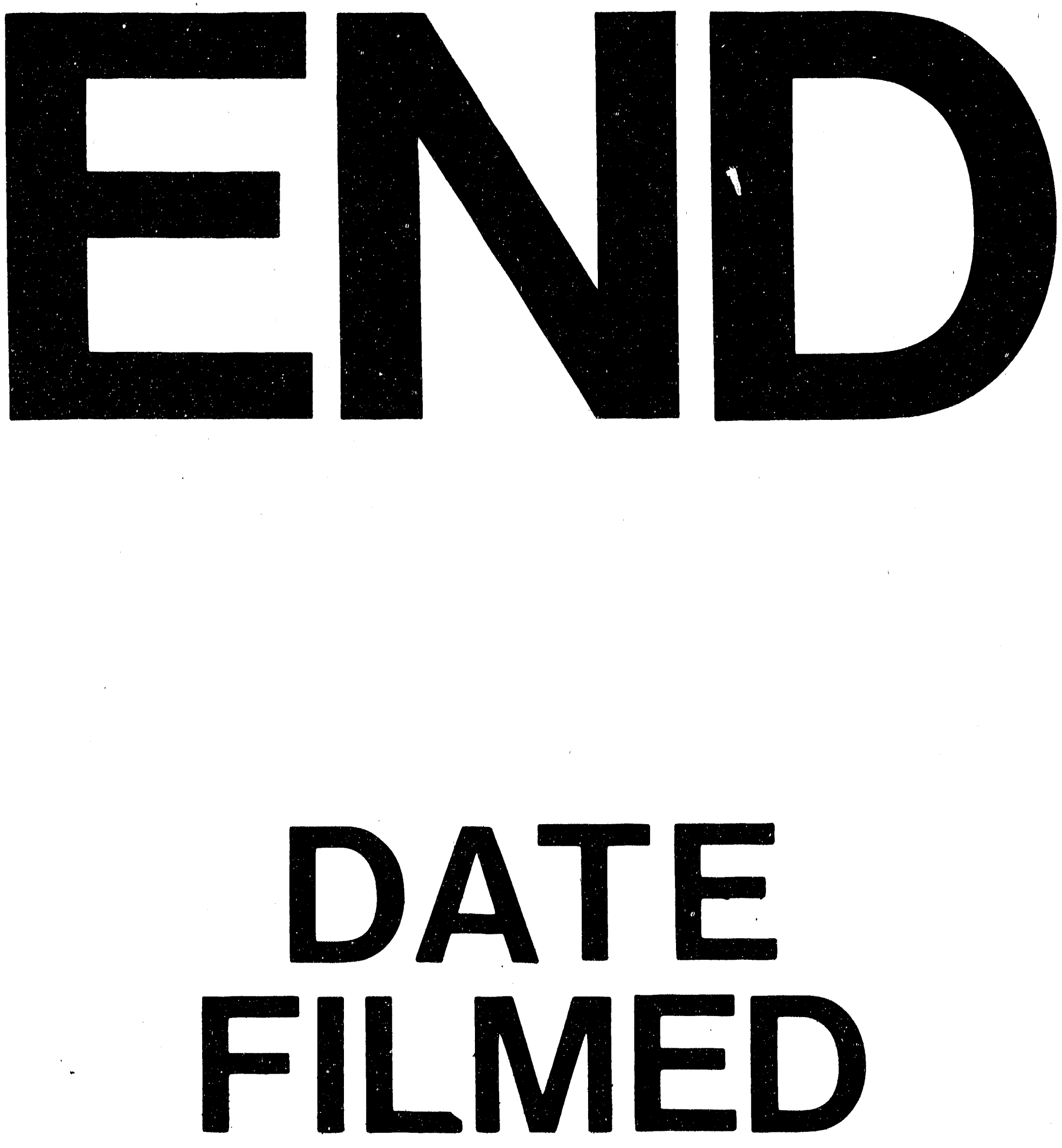

I

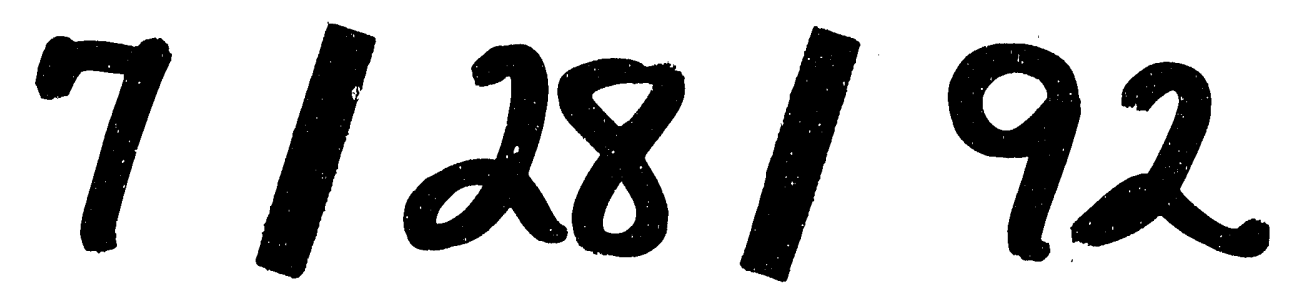


